Archive for

Organic Chemistry

Arkivoc 2020, part vii, 306-321

\title{
The synthesis and anti-inflammatory evaluation of 1,2,3-triazole linked isoflavone benzodiazepine hybrids
}

\author{
Gabriel Menghereş, ${ }^{a}$ Olumayokun Olajide, ${ }^{b}$ and Karl Hemming ${ }^{a *}$ \\ ${ }^{a}$ Department of Chemical Sciences, University of Huddersfield, Huddersfield, HD1 3DH, UK \\ ${ }^{b}$ Department of Pharmacy, University of Huddersfield, Huddersfield, HD1 3DH, UK
}

Email: k.hemming@hud.ac.uk

Dedicated to Professor Jan Bergman on the Occasion of his $80^{\text {th }}$ Birthday

Received 10-13-2020

Accepted 12-21-2020

Published on line $12-27-2020$

\section{Abstract}

Copper catalyzed azide-alkyne cycloaddition was used for the first time to access a small series of eight novel 1,2,3-triazole linked isoflavone benzodiazepine hybrids. As part of this work, a previously unreported alkyne substituted pyrrolo[1,4]benzodiazepine was synthesized using a Sonogashira coupling reaction. Two previously unreported azide substituted isoflavones were also synthesized using TMS-azide as a key reagent. The eight new 1,2,3-triazole linked products, and several precursors, were evaluated as potential anti-inflammatory compounds. This revealed that two of the triazole linked isoflavone benzodiazepine hybrids together with one of the azido-isoflavone precursors showed useful NO inhibitory activity when compared to natural isoflavones.<smiles>[R1]Oc1ccc2c(=O)c(-c3ccc(N)cc3)coc2c1</smiles>

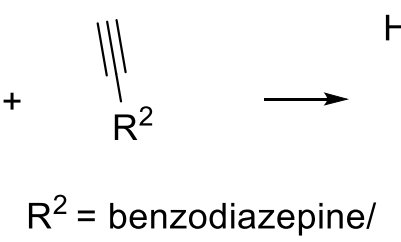

imidazobenzodiazepine/

pyrrolobenzodiazepine<smiles>CCOC(=O)c1ncn2c1C1CCCN1C(=O)c1cc(-c3cn(-c4ccc(-c5coc6cc(O)ccc6c5=O)cc4)nn3)ccc1-2</smiles>

Keywords: benzodiazepine, triazole, isoflavone, azide, anti-inflammatory, CuAAC 


\section{Introduction}

Isoflavones such as daidzein $\mathbf{1}$ and formononetin $\mathbf{2}$ (see Figure 1) are naturally occurring phytoestrogens that have long been associated with a wide range of biological activities, ${ }^{1,2}$ including anti-inflammatory ${ }^{3}$ and neuroprotective properties. ${ }^{4}$ This has led to significant interest in the synthesis of this class of compounds and their investigation as potential leads for the development of treatments for neurodegenerative disorders such as Alzheimer's disease (AD). ${ }^{4,5,6}$ The neuroprotective properties of formononetin and their pharmacological origins have been evaluated. ${ }^{5}$ Daidzein has been shown in animal studies to induce improvements in cognitive function by correcting oxidative stress in neuronal cells in the brain, ${ }^{6}$ and its hydroxylated metabolite, 6,7,4'trihydroxyisoflavone, has been shown to improve learning and memory via activation of the cholinergic system. ${ }^{7}$ It has been clearly established that neuroinflammation is a valid target in AD, and that the microglial cells produced in AD mediate neuroinflammation. ${ }^{8,9}$ The synthetic isoflavone derivative 3, shown in Figure 1 , has been established to be an anti-neuroinflammatory compound with neuroprotective properties, and has shown the ability to improve cognitive ability in an animal model, making it a promising lead compound for the treatment of AD. ${ }^{10}$

As part of an ongoing project that is looking at the synthesis and biological evaluation of novel antiinflammatory and neuroprotective small-ring heterocycles ${ }^{11}$ and isoflavones, ${ }^{12}$ and due to an interest in the chemistry of benzodiazepines, ${ }^{13}$ we have been exploring the synthesis and anti-inflammatory properties of isoflavone benzodiazepine hybrid drugs, and report our results herein. Hybrid drugs seek to covalently link two pharmacophores in one molecule, and aim to produce improved pharmacodynamic and therapeutic profiles. ${ }^{14}$ Our choice of a benzodiazepine as the partner to an isoflavone is supported by reports that chronic benzodiazepine users have a lower brain amyloid load where a reduction in neuroinflammation has been identified as the potential pathway. ${ }^{15}$ Significantly, there are also reports that the imidazobenzodiazepines $\mathbf{4}^{16,17}$ imidazobenzodiazepinones $5^{18,19}$ and their pyrrolo-fused analogues $\mathbf{6}^{20}$ (Figure 1 ) offer the potential to aid learning and memory, and may limit the underlying causes of cognitive decline and age associated hyperactivity ${ }^{19}$ associated with AD.

We favoured the use of a 1,2,3-triazole as the covalent link between the benzodiazepine and isoflavone moieties because of our familiarity with the use and synthesis of azides, ${ }^{21}$ because of their common use as a linker using very well-known click-chemistry protocols, ${ }^{14}$ and also because of the potential that they have to deliver interesting biological activity in their own right. The synthesis and use of hybrid drug candidates containing 1,2,3-triazoles has been recently and extensively reviewed, ${ }^{22}$ and the synthesis of such compounds also features strongly in a recent review of potential drug candidates for Alzheimer's disease. ${ }^{23}$ We are aware that the antimicrobial activity of novel synthetic isoflavone 1,2,3-triazole hybrids has been evaluated, ${ }^{24}$ that 1,2,3-triazole linked pyrrolobenzodiazepine dimers ${ }^{25}$ and chalcone hybrids ${ }^{26}$ have been synthesized and studied as DNA minor groove inhibitors ${ }^{25,26}$ with significant anticancer potential, as have flavone pyrrolobenzodiazepine hybrids joined by an ether link, ${ }^{27}$ and that hexahydrodibenzodiazepine 1,2,3-triazole hybrids have been reported to be butyrylcholinesterase inhibitors of interest in AD. ${ }^{28}$ However, we are aware of no reports that have investigated benzodiazepines attached to isoflavones via a 1,2,3-triazole link. In this report, we focus on the synthetic methodology that was used to construct these target molecules. We also report some preliminary biological screening data, the full details of which will be reported elsewhere. 
<smiles>[R]Oc1ccc(-c2coc3cc(O)ccc3c2=O)cc1</smiles>

$1 \mathrm{R}=\mathrm{H} ; 2 \mathrm{R}=\mathrm{Me}$<smiles>CCN(C)CCCCOc1ccc2c(=O)c(-c3ccc(OCCN4CCCCC4)cc3)coc2c1</smiles>

3<smiles>[R]c1ccc2c(c1)C([Al])=NC([R])c1c(C(Cl)Cl)ncn1-2</smiles>

4<smiles>[R][R]#Cc1ccc2c(c1)C(=O)N(C)Cc1c(C([R])=O)ncn1-2</smiles>

5<smiles>[R]C(=O)c1ncn2c1[C@H]1CCCN1C(=O)c1cc([R])ccc1-2</smiles>

6

Figure 1. Isoflavones and Benzodiazepines of Interest in AD Research.

\section{Results and Discussion}

As discussed in the Introduction, we wished to attach isoflavones to benzodiazepines using an azide-alkyne cycloaddition. The previously unreported azides 10 and 11 were obtained as shown in Scheme 1. Thus, resorcinol and 4-nitrophenylacetic acid were reacted together in the presence of $\mathrm{BF}_{3}$. Et ${ }_{2} \mathrm{O}$ to give a deoxybenzoin intermediate $\mathbf{7}$ which was formylated and cyclized in the presence of DMF and methanesulfonyl chloride using a modified literature method ${ }^{29}$ to give the known ${ }^{29,30}$ isoflavone 8 . Reduction to the corresponding previously reported ${ }^{29,30}$ amine $\mathbf{9}$ was followed by diazotization and azidation with TMS-azide to give the previously unknown azide $\mathbf{1 0}$ which was reacted readily with acetic anhydride in pyridine to give the unknown acylated analogue 11.<smiles>O=C(O)Cc1ccc([N+](=O)[O-])cc1</smiles>

2. $t$-BUONO, $\mathrm{TMSN}_{3}$, $\mathrm{MeCN}, 0^{\circ} \mathrm{C}$ to $\mathrm{RT}$<smiles>[X]c1ccc(-c2coc3cc(O)ccc3c2=O)cc1</smiles>

9, $\mathrm{X}=\mathrm{NH}_{2} 66 \%$ (step 1); $10, X=N_{3} 75 \%$ (step 2)

Scheme 1. The Synthesis of Azido Isoflavones. 
As reaction partners for the two isoflavone based azides 10 and $\mathbf{1 1}$, we required the alkyne substituted imidazobenzodiazepines 5 and $\mathbf{6}\left(\mathrm{R}^{2}=\mathrm{C} \equiv \mathrm{CH}\right)$, the syntheses of which are shown in Scheme 2. The imidazofused systems were selected due to the association of these compounds with cognitive enhancement and their potential usefulness ${ }^{19}$ in treating the symptoms of $A D$, as discussed in the Introduction. Thus, isatoic anhydride 12 was reacted with the amino acids 13 and 14 to give the known benzodiazepinediones $15^{31}$ and $16^{32}$ which were brominated regioselectively to give the previously reported intermediates $17^{33}$ and $18{ }^{34}$ Condensation of $\mathbf{1 7}$ and $\mathbf{1 8}$ with ethyl isocyanoacetate $\mathbf{2 0}$ in the presence of chlorophosphate 19 proceeded without incident to furnish the known imidazobenzodiazepines $\mathbf{2 1}{ }^{33,35}$ and $\mathbf{2 2}$. $^{35}$ The bromobenzodiazepines 17, 18, 21 and 22 were then subjected to Sonogashira couplings with the (trialkylsilyl)acetylenes 23 and 24 , yielding the (trialkylsilyl)ethynyl-substituted benzodiazepines 25 - 31. TBAF mediated deprotection produced the desired ethynyl-substituted benzodiazepines 32 - 35. Compounds $26-30$ and 35 are previously unreported, whereas compounds $25,{ }^{36} \mathbf{3 1},{ }^{18} \mathbf{3 2},{ }^{37} \mathbf{3 3 ^ { 1 9 , 3 6 }}$ and $\mathbf{3 4 ^ { 1 8 }}$ have been reported. We chose to work with the known imidazo-fused systems $\mathbf{3 3}$ and $\mathbf{3 4}$ as reaction partners for the reasons described above. Compounds $\mathbf{3 2}$ and $\mathbf{3 5}$ were synthesized due to their ease of access from bromo-precursors 17 and 18, and to provide useful comparators for later biological testing. It is also of note that, as far as we are aware, the alkynyl pyrrolobenzodiazepine $\mathbf{3 5}$ together with its precursor trialkylsilyl alkynes $\mathbf{2 9}$ and $\mathbf{3 0}$ have not been reported before. Similarly, trialkylsilyl alkynes $\mathbf{2 7}$ and $\mathbf{2 8}$ are not known in the literature, although the alkyne $\mathbf{3 2}$ has been reported in the patent literature, where it was accessed via an alkyne substituted derivative of isatoic anhydride $12 .{ }^{37}$

With the requisite alkynes $\mathbf{3 2}$ - $\mathbf{3 5}$ and azides 10 and 11 in hand, eight new 1,2,3-triazoles $\mathbf{3 6}$ - 43 were produced by reaction in the presence of a $\mathrm{Cu}(\mathrm{II}) /$ ascorbate system, as shown in Scheme 3 and Table 1 . The copper catalyzed azide-alkyne cycloadditions did not occur after reaction for two days at room temperature, showed no reaction after 24 hours at $50{ }^{\circ} \mathrm{C}$, and showed only a small amount of product after 24 hours at 80 ${ }^{\circ} \mathrm{C}$. It was found that $100{ }^{\circ} \mathrm{C}$ overnight (16 hours) was required for complete reactions to occur. No reaction was observed in the absence of copper, with toluene at reflux either returning the starting materials or, on prolonged heating, causing loss of the azide starting material by degradation.

The new triazole compounds were produced in sufficient purity ( $>95 \%$ by ${ }^{1} \mathrm{H} N M R$ ) and amounts (10s of milligrams were produced, but only $\mu \mathrm{Ls}$ of a $10 \mathrm{mM}$ solution were used) for our biological testing requirements, which are described below. However, whilst all of the products were sufficiently soluble in DMSO to allow biological testing, the acetylated triazoles $\mathbf{4 0}-\mathbf{4 3}$ were not sufficiently soluble to allow ${ }^{13} \mathrm{C}$ NMR spectra to be recorded, and only just soluble enough to allow ${ }^{1} \mathrm{H} N M R$ data collection (see the Experimental Section and Supplementary Material). Nonetheless, for compounds $40-43$, the ${ }^{1} \mathrm{H}$ NMR data showed that the $\mathrm{Cu}(\mathrm{II})$ /ascorbate mediated cycloaddition reaction had clearly succeeded, a conclusion that was supported by the infra-red and HRMS data. All other compounds were fully characterized. 
<smiles></smiles>
(e): 19, 20<smiles>C#Cc1ccc2c(c1)C(=O)N1CCCC1C(=O)N2</smiles>

35 (95\% from 29; $90 \%$ from 30 )<smiles>CN1CC(=O)Nc2ccccc2C1=O</smiles>
$15(75 \%)$<smiles>CCC</smiles>
13<smiles>[CH]1CCCCC1</smiles><smiles>[R3][SiH2]C#Cc1ccc2c(c1)C(=O)N1CCCC1C(=O)N2</smiles>

29, $\mathrm{R}=\mathrm{Me}(88 \%)$

$30, \mathrm{R}=\mathrm{Et}(85 \%)$ $\frac{(c)}{\begin{array}{c}23 \text { or } \\ 24\end{array}}$

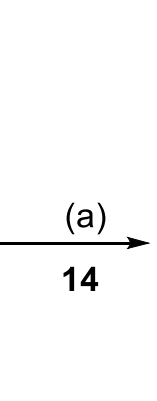<smiles>O=C1Nc2ccc(Br)cc2C(=O)N2CCCC12</smiles>

$18(70 \%)$ (b)<smiles>CN1CC(=O)Nc2ccc(Br)cc2C1=O</smiles>
$17(60 \%)$ (e): 19, 20

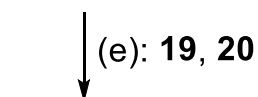

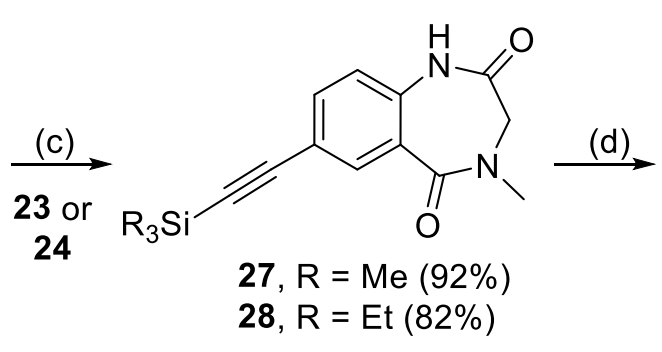

$27, \mathrm{R}=\mathrm{Me}(92 \%)$

(d)<smiles>C#Cc1ccc2c(c1)C(=O)N(C)CC(=O)N2</smiles>

32 (84\% from 27 $94 \%$ from 28

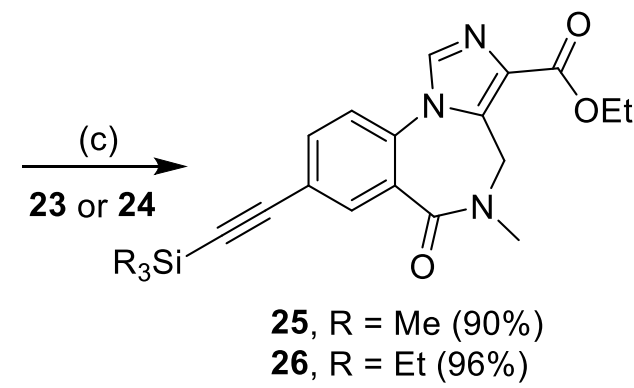<smiles>C#Cc1ccc2c(c1)C(=O)N(C)Cc1c(C(=O)OCC)ncn1-2</smiles>

33 (92\% from 21

$81 \%$ from 22 )<smiles>C#C[SiH2]C</smiles>

23<smiles>C#C[SiH2]CC</smiles>

24<smiles>CNCC(=O)O</smiles>

13<smiles>O=C(O)C1CCCN1</smiles>

14<smiles>CCOP(=O)(Cl)OCC</smiles>

19<smiles>[C-]#[N+]CC(=O)OCC</smiles>

20

Scheme 2. Synthesis of Benzodiazepine Derivatives. Reagents and conditions: (a) 13 or $\mathbf{1 4}$, DMSO, $120^{\circ} \mathrm{C}, 4 \mathrm{~h}$; (b) $\mathrm{Br}_{2}, \mathrm{NaOAc}, \mathrm{AcOH}, \mathrm{RT}, 16 \mathrm{~h}$; (c) 1. TEA, $\mathrm{CH}_{3} \mathrm{CN}, 70^{\circ} \mathrm{C}$; 2 . [Pd( $\left.\left(\mathrm{PPh}_{3}\right)_{2} \mathrm{Cl}_{2}\right], 23$ or 24, $85^{\circ} \mathrm{C}, 20 \mathrm{~h}$; (d) TBAF, THF, $\mathrm{RT}, 15 \mathrm{~min}$; (e) 1. $t$-BuOK, THF, $0{ }^{\circ} \mathrm{C}, 20 \mathrm{~min} ; 2.19,-35^{\circ} \mathrm{C} ; 3.0^{\circ} \mathrm{C}, 30 \mathrm{~min} ; 4.20, t$-BuOK, $-35^{\circ} \mathrm{C} ; 5 . \mathrm{RT}, 4 \mathrm{~h}$. 
$\mathrm{R}^{1} \mathrm{O}$<smiles>Cc1ccc2c(=O)c(-c3ccc(N)cc3)coc2c1</smiles>

10, $\mathrm{R}^{1}=\mathrm{H} ; 11, \mathrm{R}^{1}=\mathrm{CH}_{3} \mathrm{CO}$

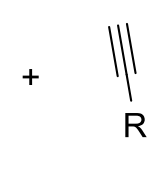

$32-35$
$\mathrm{CuSO}_{4} \cdot 5 \mathrm{H}_{2} \mathrm{O}$ ( 0.05 equiv), sodium ascorbate ( 0.2 equiv),

$\mathrm{H}_{2} \mathrm{O} /$ tert-butanol (2:1 ratio), $100{ }^{\circ} \mathrm{C}, 16 \mathrm{~h}$

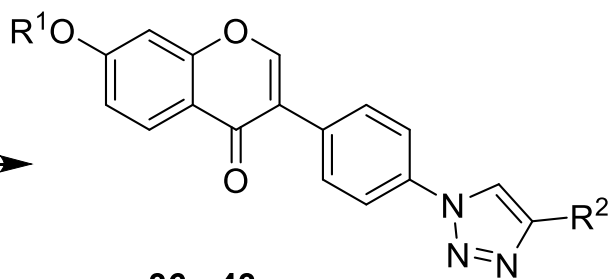

$36-43$

Scheme 3. Synthesis of Novel 1,4-Disubstituted 1,2,3-Triazoles.

Table 1. Synthesis of Novel 1,4-Disubstituted 1,2,3-Triazoles

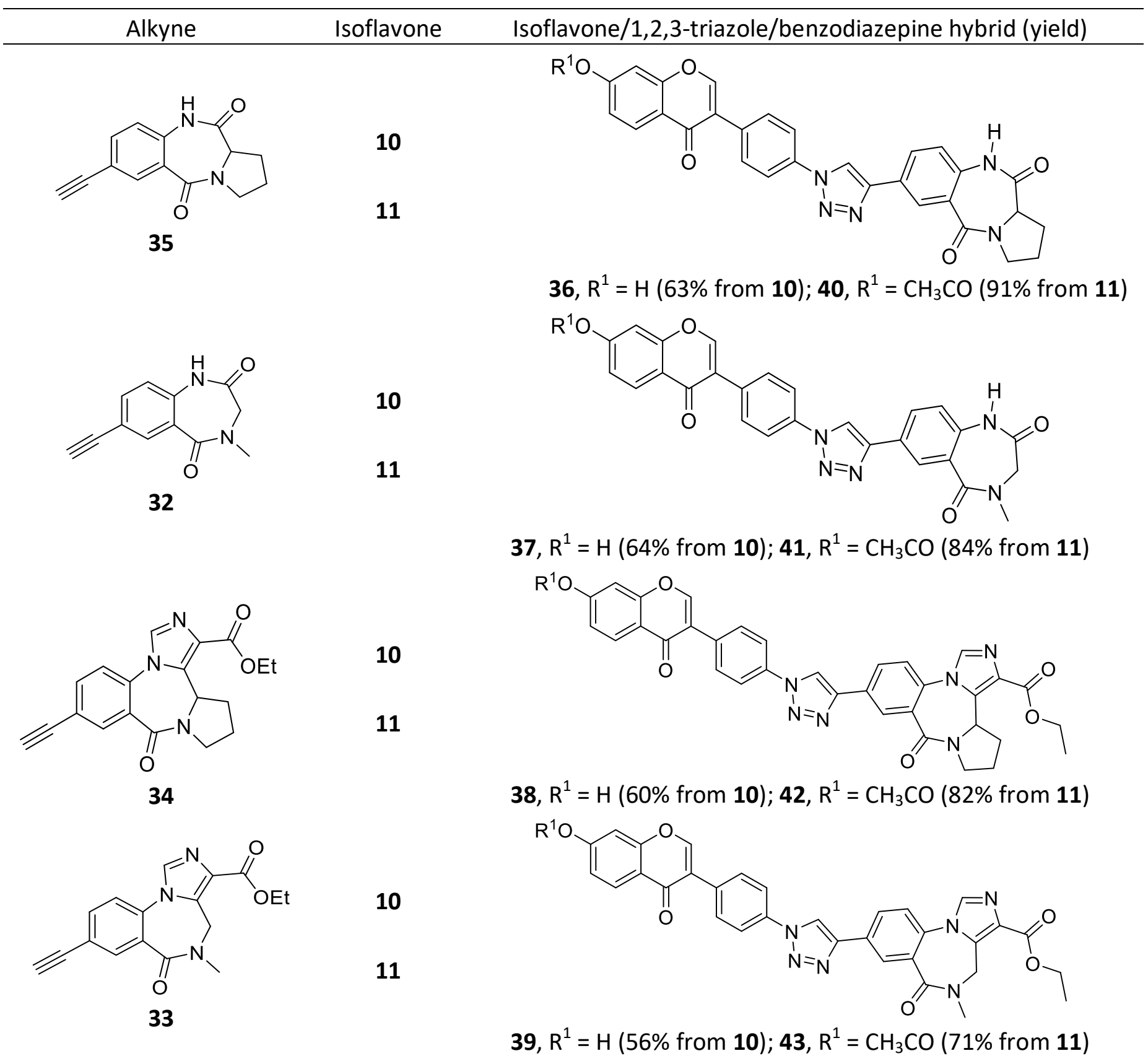

The 1,2,3-triazoles 36 - 43, together with some key precursors and the original natural products $\mathbf{1}$ and $\mathbf{2}$, were evaluated in vitro on LPS-stimulated BV2 mouse brain microglial cells as a preliminary screen for 
potential anti-inflammatory compounds, and the results are summarized in Table 2. Cell viability was performed using XTT assay ${ }^{38}$ in order to determine if the compounds were toxic to the BV2 cells. BV2 mouse brain microglial cells are commonly used in place of primary microglia, ${ }^{39}$ and have a key role in neuroinflammation. ${ }^{40}$ When microglia are activated, for example, with LPS (lipopolysaccharide), proinflammatory mediators such as nitric oxide are produced. ${ }^{41}$ Activated microglia have been found next to amyloid $\beta$ plaques in Alzheimer's disease, ${ }^{42}$ and are a recognized target for reducing inflammation and neurodegeneration. Nitric oxide production was measured using the Griess Assay. ${ }^{43} \mathrm{NO}$ is produced in small amounts by normal cells (Table 2 - entries 1 and 2: 20\% NO production), but when the cells are LPS-activated, NO production increases significantly (Table 2, entry 3: 100\% NO production). Table 2 shows that two of the novel hybrids (39 and 43), both derived from the imidazobenzodiazepine $\mathbf{3 3}$, showed reasonable cell viability (>60\%) and significant inhibition of NO production (<20\%), when compared to the known anti-inflammatory natural products daidzein 1 and formononetin 2, and so were selected for further pharmacological evaluation. The alkynyl benzodiazepines $\mathbf{3 2}$ - 35 were not cytotoxic but did not inhibit LPS-induced NO production when compared to daidzein $\mathbf{1}$ and formononetin $\mathbf{2}$. The previously unreported azide $\mathbf{1 0}$ also showed good inhibition of NO production when compared to daidzein $\mathbf{1}$ and formononetin $\mathbf{2}$, and so was selected for further study. We will report the results and full details of these ongoing pharmacological studies elsewhere, as it is beyond the remit of this journal.

Table 2. In vitro cell viability and NO production for Triazoles 36 - 43 and Selected Precursors

\begin{tabular}{|c|c|c|c|}
\hline Compound No & Cell viability \pm SEM $(\%)^{a}$ & NO production \pm SEM $(\%)^{b}$ & MW \\
\hline$--^{c}$ & $107.46 \pm 3.04$ & $20.89 \pm 0.79$ & \\
\hline - DMSO & $100.00 \pm 0.00$ & $20.08 \pm 0.71$ & \\
\hline$+{ }^{d}$ & $83.52 \pm 1.73$ & $100.00 \pm 0.00$ & \\
\hline Daidzein, $1^{\mathrm{e}}$ & $106.63 \pm 2.18$ & $34.79 \pm 2.43$ & 254.24 \\
\hline Formononetin, 2 & $84.83 \pm 5.59$ & $72.70 \pm 4.64$ & 268.26 \\
\hline 10 & $63.07 \pm 4.15$ & $29.09 \pm 1.95$ & 279.25 \\
\hline 11 & $52.87 \pm 7.80$ & $31.40 \pm 4.26$ & 321.29 \\
\hline 32 & $100.21 \pm 3.89$ & $95.73 \pm 10.00$ & 214.22 \\
\hline 33 & $87.03 \pm 2.30$ & $82.87 \pm 8.90$ & 309.32 \\
\hline 34 & $115.97 \pm 1.73$ & $90.06 \pm 8.49$ & 335.36 \\
\hline 35 & $89.26 \pm 4.64$ & $96.70 \pm 9.22$ & 240.26 \\
\hline 36 & $39.34 \pm 8.65$ & $29.45 \pm 2.75$ & 519.51 \\
\hline 37 & $67.74 \pm 5.13$ & $51.6 \pm 23.67$ & 493.47 \\
\hline 38 & $42.85 \pm 6.51$ & $18.06 \pm 1.00$ & 614.61 \\
\hline 39 & $66.35 \pm 9.97$ & $19.99 \pm 1.07$ & 588.57 \\
\hline 40 & $97.73 \pm 13.76$ & $64.28 \pm 1.02$ & 561.54 \\
\hline 41 & $45.68 \pm 3.20$ & $18.15 \pm 0.96$ & 535.51 \\
\hline 42 & $44.62 \pm 7.50$ & $17.76 \pm 0.94$ & 656.64 \\
\hline 43 & $60.24 \pm 5.79$ & $19.88 \pm 1.23$ & 630.61 \\
\hline
\end{tabular}


Table 2. Continued

${ }^{a}$ For cell viability, the \% values are reported relative to negative control cells DMSO (DMSO, 100\%) that contained the amount of DMSO used to add the compound solutions in the cell medium. ${ }^{\mathrm{b}}$ For NO production, the \% values are reported relative to LPS-stimulated BV2 cells (+, 100\%). ' Negative control, - : BV2 cells were incubated for $24 \mathrm{~h}$ only with serum free medium RPMI. ${ }^{\mathrm{d}}$ LPS-stimulated cells, + : BV2 cells were incubated for $24 \mathrm{~h}$ with $100 \mathrm{ng} / \mathrm{mL}$ LPS in the medium. ${ }^{\mathrm{e}}$ Compounds: BV2 cells were incubated with the compounds at a concentration of $20 \mu \mathrm{M}$ (final concentration in well) and stimulated with $100 \mathrm{ng} / \mathrm{mL}$ LPS. Values are expressed as mean \pm SEM (\%) of minimum three experiments; SEM is standard error of mean. MW: molecular weight.

\section{Conclusions}

A series of 8 novel 1,2,3-triazole linked benzodiazepine substituted isoflavones was produced in $56-91 \%$ yield using a copper catalyzed azide-alkyne cycloaddition reaction between two previously unreported azidoisoflavones and four alkynyl-1,4-benzodiazepines. The alkynes were produced in good to excellent overall yields using Sonogashira couplings. The cell viability and inhibition of NO production in LPS-stimulated BV2 cells were determined for the novel triazole products and their precursors, and the results were compared to the parent natural products daidzein and formononetin. Two of the new 1,2,3-triazole linked benzodiazepine substituted isoflavones, both derived from the same imidazobenzodiazepine, and one of the azido-isoflavones, showed useful levels of activity (inhibition of NO production in LPS-stimulated BV2 cells greater than daidzein and much greater than formononetin) and are candidates for further pharmacological evaluation, the results of which will appear elsewhere.

\section{Experimental Section}

General. Reagents and anhydrous solvents were purchased from Fischer Scientific, Acros Organics, SigmaAldrich, VWR, Manchester Organics, Fluorochem and Alfa-Aesar, and were used as supplied, unless otherwise indicated. Compounds $\mathbf{8},{ }^{29,30} \mathbf{9},{ }^{29,30} \mathbf{1 6},{ }^{44} \mathbf{1 8},{ }^{34} \mathbf{2 2},{ }^{35} \mathbf{3 1},{ }^{18} \mathbf{3 4},{ }^{18} \mathbf{1 5},{ }^{31} \mathbf{1 7},{ }^{23} \mathbf{3 2},{ }^{37} \mathbf{2 1},{ }^{35} \mathbf{2 5 ^ { 3 6 }}$ and $33^{36}$ are known and were synthesized as described in the Supplementary Information using the relevant literature method. The compounds reported below are all previously unreported.

Reactions were magnetically stirred, heated on a paraffin oil bath, and monitored on Merck TLC silica gel 60 $\mathrm{F}_{254}$ aluminium sheets. Visualization of spots was accomplished using a UV lamp (254 or $365 \mathrm{~nm}$ ) and/or staining with potassium permanganate solution. Column chromatography was performed on silica gel (Aldrich, technical grade, pore size $60 \AA, 40-63 \mu \mathrm{m}$ particle size) using the solvent mixtures indicated (volume to volume ratios). Unless otherwise indicated, reactions were conducted under an atmosphere of dry nitrogen.

Nuclear magnetic resonance (NMR) spectra were recorded on Bruker Ascend $400\left(400 \mathrm{MHz}-{ }^{1} \mathrm{H}\right.$, and $100 \mathrm{MHz}$ $\left.-{ }^{13} \mathrm{C}\right)$, Bruker Fourier $300\left(300 \mathrm{MHz}-{ }^{1} \mathrm{H}\right.$, and $\left.75 \mathrm{MHz}-{ }^{13} \mathrm{C}\right)$, Bruker Avance $500\left(500 \mathrm{MHz}-{ }^{1} \mathrm{H}\right.$, and $125 \mathrm{MHz}-$ $\left.{ }^{13} \mathrm{C}\right)$ or Bruker Avance $600\left(600 \mathrm{MHz}-{ }^{1} \mathrm{H}\right.$, and $\left.150 \mathrm{MHz}-{ }^{13} \mathrm{C}\right)$ spectrometers using $\mathrm{CDCl}_{3},\left(\mathrm{CD}_{3}\right){ }_{2} \mathrm{SO}_{2}\left(\mathrm{CD}_{3}\right)_{2} \mathrm{CO}$, $\mathrm{CD}_{3} \mathrm{OD}$ or $\mathrm{D}_{2} \mathrm{O}$ as solvent and as internal standard. The chemical shifts $(\delta)$ are expressed in parts per million (ppm). The multiplicities were reported as $s=$ singlet, $d=$ doublet, $t=$ triplet, $q=$ quartet, $b r=b r o a d$ signal, combinations of aforementioned multiplicities, and $\mathrm{m}=$ multiplet. Mass spectral experiments were performed 
on Agilent 6210 TOF MS (Dual ESI source), Agilent 6530 Q-TOF MS (Jet Stream ESI source), Agilent 1290 HPLC + 6530 Q-TOF (Dual AJSESI source +ve) or Agilent 7890A-5975C (EI-GCMS) and spectra were recorded in positive mode. FT-IR spectra were recorded on a Thermo Nicolet 380 FT-IR Spectrometer with Diamond ATR (neat sample). Melting points were recorded using a Stuart SMP10 melting point apparatus.

3-(4-Azidophenyl)-7-hydroxy-4H-chromen-4-one (10). To a suspension of aminoisoflavone 9 (2.96 mmol, 750 $\mathrm{mg}$ ) in anhydrous acetonitrile $(6 \mathrm{~mL})$ at $0{ }^{\circ} \mathrm{C}, t$-BuONO $(4.44 \mathrm{mmol}, 458 \mathrm{mg}, 0.59 \mathrm{~mL})$ and TMSN $\mathrm{TM}_{3}(4.44 \mathrm{mmol}$, $512 \mathrm{mg}, 0.62 \mathrm{~mL}$ ) were added dropwise, and the resulting mixture was stirred at room temperature for $1.5 \mathrm{~h}$. The solvent was removed by rotary evaporation to give a crude product that was washed with $\mathrm{CH}_{2} \mathrm{Cl}_{2}(20 \mathrm{~mL})$ to give azide 10 (725 mg, $75 \%$ ) as a white solid; $\mathrm{mp} 198{ }^{\circ} \mathrm{C}$ (decomp.); $R_{f}=0.4\left(\mathrm{CH}_{2} \mathrm{Cl}_{2} / \mathrm{CH}_{3} \mathrm{OH}, 95: 5\right)$.

${ }^{1} \mathrm{H}-\mathrm{NMR}\left(400 \mathrm{MHz}, d_{6}\right.$-DMSO): $\delta 10.84(\mathrm{~s}, 1 \mathrm{H}, \mathrm{OH}), 8.41(\mathrm{~s}, 1 \mathrm{H}), 7.96(\mathrm{~d}, 8.8 \mathrm{~Hz}, 1 \mathrm{H}), 7.61(\mathrm{~d}, J 8.5 \mathrm{~Hz}, 2 \mathrm{H})$, $7.17(\mathrm{~d}, J 8.5 \mathrm{~Hz}, 2 \mathrm{H}), 6.93$ (dd, J 2.2, $8.8 \mathrm{~Hz}, 1 \mathrm{H}), 6.87$ (d, J $2.2 \mathrm{~Hz}, 1 \mathrm{H}) .{ }^{13} \mathrm{C}-\mathrm{NMR}\left(100 \mathrm{MHz}, d_{6}-\mathrm{DMSO}\right): \delta=$ $174.8(\mathrm{C}=0), 163.2(\mathrm{qC}), 157.9(\mathrm{qC}), 154.3(\mathrm{CH}), 139.3(\mathrm{qC}), 130.9(2 \mathrm{CH}), 129.4(\mathrm{qC}), 127.8(\mathrm{CH}), 123.1(\mathrm{qC})$, $119.3(2 \mathrm{CH}), 117.0(\mathrm{qC}), 115.8(\mathrm{CH}), 102.6(\mathrm{CH})$. HRMS (Dual ESI): calc $\mathrm{m} / \mathrm{z}$ for $\mathrm{C}_{15} \mathrm{H}_{9} \mathrm{~N}_{3} \mathrm{O}_{3}: 279.0644$ [M], $280.0717[\mathrm{M}+\mathrm{H}]^{+}, 252.0661\left[\mathrm{M}-\mathrm{N}_{2}\right]^{+}$; found: $279.0648[\mathrm{M}], 280.0720[\mathrm{M}+\mathrm{H}]^{+}, 252.0665\left[\mathrm{M}-\mathrm{N}_{2}\right]^{+} . \mathrm{FT}-\mathrm{IR}\left(\mathrm{cm}^{-1}\right): \mathrm{u}$ $=3232$, 3050, 2099, 1619, 1575, 1565, 1506, 1376, 1264, 1093, 829.

3-(4-Azidophenyl)-4-oxo-4H-chromen-7-yl acetate (11). To a solution of azide 10 (1.79 mmol, $500 \mathrm{mg}) \mathrm{in}$ pyridine $(3.6 \mathrm{~mL})$, acetic anhydride $(17.9 \mathrm{mmol}, 1.7 \mathrm{~mL})$ was added dropwise, and the resulting mixture was stirred at RT for $4 \mathrm{~h}$. Water $(20 \mathrm{~mL})$ was added and the mixture was extracted with $\mathrm{CH}_{2} \mathrm{Cl}_{2}(3 \times 25 \mathrm{~mL})$. The organic extracts were dried $\left(\mathrm{MgSO}_{4}\right)$, filtered, and concentrated under reduced pressure. The crude product was purified by flash chromatography $\left(\mathrm{CH}_{2} \mathrm{Cl}_{2} / \mathrm{CH}_{3} \mathrm{OH}, 100: 1\right)$ to give compound $\mathbf{1 1}$ (490 mg, 85\%) as a white solid; mp 179-180 ${ }^{\circ} \mathrm{C} ; R_{f}=0.7\left(\mathrm{CH}_{2} \mathrm{Cl}_{2} / \mathrm{CH}_{3} \mathrm{OH}, 100: 1\right) .{ }^{1} \mathrm{H}-\mathrm{NMR}\left(400 \mathrm{MHz}, \mathrm{CDCl}_{3}\right): \delta=8.32(\mathrm{~d}, J 8.7 \mathrm{~Hz}, 1 \mathrm{H})$, $8.00(\mathrm{~s}, 1 \mathrm{H}), 7.56(\mathrm{~d}, J 8.5 \mathrm{~Hz}, 2 \mathrm{H}), 7.31(\mathrm{~d}, J 2.1 \mathrm{~Hz}, 1 \mathrm{H}), 7.18(\mathrm{dd}, J 2.1,8.7 \mathrm{~Hz}, 1 \mathrm{H}), 7.10(\mathrm{~d}, J 8.5 \mathrm{~Hz}, 2 \mathrm{H})$, $2.36(\mathrm{~s}, 3 \mathrm{H}, \mathrm{Me}) .{ }^{13} \mathrm{C}-\mathrm{NMR}\left(100 \mathrm{MHz}, \mathrm{CDCl}_{3}\right): \delta=175.6(\mathrm{C}=\mathrm{O}), 168.7(\mathrm{C}=0), 156.7(\mathrm{qC}), 154.6(\mathrm{qC}), 153.1(\mathrm{CH})$, $140.2(q C), 130.4(2 \mathrm{CH}), 128.3(\mathrm{qC}), 127.9(\mathrm{CH}), 124.8(\mathrm{qC}), 122.3(\mathrm{qC}), 119.7(\mathrm{CH}), 119.2(2 \mathrm{CH}), 111.1(\mathrm{CH})$, $21.3\left(\mathrm{CH}_{3}\right)$.

HRMS (Jet stream ESI): calc $m / z$ for $\mathrm{C}_{17} \mathrm{H}_{11} \mathrm{~N}_{3} \mathrm{O}_{4}: 321.0750$ [M], 344.0642 [M+Na] ; found: 321.0762 [M], $344.0643[\mathrm{M}+\mathrm{Na}]^{+}$. FT-IR $\left(\mathrm{cm}^{-1}\right): \mathrm{v}=3088,3047,2980,2121,1750,1620,1576,1506,1440,1360,1287,1241$, 1211, 1183, 1098.

\section{7-((Trimethylsilyl)ethynyl)-1,2,3,11a-tetrahydro-5H-benzo[e]pyrrolo[1,2-a][1,4]diazepine-5,11(10H)-dione}

(29). To a degassed solution of 7-bromobenzodiazepine 18 (1.7 mmol. $502 \mathrm{mg}, 1.0$ equiv.) in $\mathrm{Et}_{3} \mathrm{~N}(25 \mathrm{~mL})$ and $\mathrm{CH}_{3} \mathrm{CN}(20 \mathrm{~mL})$, at $70{ }^{\circ} \mathrm{C}, \mathrm{PdCl}_{2}\left(\mathrm{PPh}_{3}\right)_{2}(0.17 \mathrm{mmol}, 120 \mathrm{mg}, 10 \mathrm{~mol} \%)$ and (trimethylsilyl)acetylene 23 (3.4 mmol, $334 \mathrm{mg}, 0.47 \mathrm{~mL}$ ) were added. After stirring the resulting mixture for $20 \mathrm{~h}$ at $85{ }^{\circ} \mathrm{C}$ under $\mathrm{N}_{2}$, the solution was concentrated by rotary evaporation. Saturated aqueous $\mathrm{NaHCO}_{3}(50 \mathrm{~mL})$ was added and the crude was extracted with $\mathrm{CH}_{2} \mathrm{Cl}_{2}(3 \times 30 \mathrm{~mL})$. The organic phase was dried $\left(\mathrm{MgSO}_{4}\right)$, filtered, and concentrated under reduced pressure. The crude product was purified by flash chromatography $\left(\mathrm{CH}_{2} \mathrm{Cl}_{2} / \mathrm{CH}_{3} \mathrm{OH}, 100: 1\right)$ to give silylalkyne 29 (467 mg, 88\%) as a pale white solid; $\mathrm{mp} 223-224{ }^{\circ} \mathrm{C} ; R_{f}=0.37\left(\mathrm{CH}_{2} \mathrm{Cl}_{2} / \mathrm{CH}_{3} \mathrm{OH}, 100: 2\right)$.

${ }^{1} \mathrm{H}-\mathrm{NMR}\left(400 \mathrm{MHz}, \mathrm{CDCl}_{3}\right): \delta=9.45$ (bs, $\left.1 \mathrm{H}, \mathrm{NH}\right), 8.07$ (d, J $\left.1.8 \mathrm{~Hz}, 1 \mathrm{H}\right), 7.49$ (dd, J 1.8, $\left.8.3 \mathrm{~Hz}, 1 \mathrm{H}\right), 7.00(\mathrm{~d}, J$ $8.3 \mathrm{~Hz}, 1 \mathrm{H}$ ), 4.04 (app d, J $6.9 \mathrm{~Hz}, 1 \mathrm{H}, \mathrm{NCH}), 3.79-3.75(\mathrm{~m}, 1 \mathrm{H}, \mathrm{NCHH}), 3.55-3.60(\mathrm{~m}, 1 \mathrm{H}, \mathrm{NCHH}), 2.74-$ $2.76(\mathrm{~m}, 1 \mathrm{H}, \mathrm{CHH}), 2.05-2.00\left(\mathrm{~m}, 3 \mathrm{H}, \mathrm{CH}_{2}+\mathrm{CHH}\right), 0.22\left(\mathrm{~s}, 9 \mathrm{H}, \mathrm{SiMe}_{3}\right) .{ }^{13} \mathrm{C}-\mathrm{NMR}\left(100 \mathrm{MHz}, \mathrm{CDCl}_{3}\right): \delta=171.3$ (qC, $\mathrm{C}=\mathrm{O}), 164.7$ (qC, $\mathrm{C}=\mathrm{O}), 135.4(\mathrm{CH}), 135.3(\mathrm{qC}), 135.0(\mathrm{CH}), 126.9(\mathrm{qC}), 121.2(\mathrm{CH}), 120.1(\mathrm{qC}), 103.4(\mathrm{qC})$, $95.5(\mathrm{qC}), 56.8(\mathrm{CH}), 47.5\left(\mathrm{CH}_{2}\right), 26.3\left(\mathrm{CH}_{2}\right), 23.5\left(\mathrm{CH}_{2}\right), 0.0\left(3 \mathrm{CH}_{3}\right)$. HRMS (Dual ESI): calc $m / z$ for $\mathrm{C}_{17} \mathrm{H}_{20} \mathrm{~N}_{2} \mathrm{O}_{2} \mathrm{Si}$ : $312.1294[\mathrm{M}], 313.1367[\mathrm{M}+\mathrm{H}]^{+}$; found: $312.1292[\mathrm{M}], 313.1365[\mathrm{M}+\mathrm{H}]^{+} . \mathrm{FT}-\mathrm{IR}\left(\mathrm{cm}^{-1}\right): \mathrm{v}=3229,3139,2952$, 2897, 2154, 1692, 1632, 1604, 1491, 1436, 1374, 1247, 967. 
7-((Triethylsilyl)ethynyl)-1,2,3,11a-tetrahydro-5H-benzo[e]pyrrolo[1,2-a][1,4]diazepine-5,11(10H)-dione (30) Prepared as described for compound 29 using 7-bromobenzodiazepine 18 (0.68 mmol, $200 \mathrm{mg}), \mathrm{Et}_{3} \mathrm{~N}(15 \mathrm{~mL}$ ), $\mathrm{CH}_{3} \mathrm{CN}(12 \mathrm{~mL}), \mathrm{PdCl}_{2}\left(\mathrm{PPh}_{3}\right)_{2}(34 \mu \mathrm{mol}, 24 \mathrm{mg}, 5 \mathrm{~mol} \%)$ and (triethylsilyl)acetylene 24 (1.36 mmol, $190 \mathrm{mg}$, $0.27 \mathrm{~mL}$ ); purified by flash chromatography (EtOAc/PE, 2:3) to give compound 30 (205 $\mathrm{mg}, 85 \%$ ) as a pale brown oily solid; $R_{f}=0.24$ (EtOAc/PE, 1:1) which was characterized by NMR and used immediately in the next step.

${ }^{1} \mathrm{H}-\mathrm{NMR}\left(400 \mathrm{MHz}, \mathrm{CDCl}_{3}\right): \delta=8.14(\mathrm{~d}, J 1.9 \mathrm{~Hz}, 1 \mathrm{H}), 7.97(\mathrm{~s}, 1 \mathrm{H}, \mathrm{NH}), 7.56(\mathrm{dd}, J$ 1.9, $8.3 \mathrm{~Hz}, 1 \mathrm{H}), 6.92(\mathrm{~d}, J 8.3$ $\mathrm{Hz}, 1 \mathrm{H}), 4.07(\mathrm{~d}, J 6.6 \mathrm{~Hz}, 1 \mathrm{H}, \mathrm{NCH}), 3.87-3.81(\mathrm{~m}, 1 \mathrm{H}, \mathrm{NCHH}), 3.67-3.60(\mathrm{~m}, 1 \mathrm{H}, \mathrm{NCHH}), 2.80-2.78(\mathrm{~m}, 1$ $\mathrm{H}, \mathrm{CHH}), 2.06-2.04\left(\mathrm{~m}, 3 \mathrm{H}, \mathrm{CHH}+\mathrm{CH}_{2}\right), 1.06\left(\mathrm{t}, J 7.9 \mathrm{~Hz}, 9 \mathrm{H}, 3 \times \mathrm{SiCH}_{2} \mathrm{CH}_{3}\right), 0.69(\mathrm{q}, J 7.9 \mathrm{~Hz}, 6 \mathrm{H}, 3 \times$ $\left.\mathrm{SiCH}_{2} \mathrm{Me}\right)$.

${ }^{13} \mathrm{C}-\mathrm{NMR}\left(100 \mathrm{MHz}, \mathrm{CDCl}_{3}\right): \delta=170.6(\mathrm{qC}, \mathrm{C}=\mathrm{O}), 164.5(\mathrm{qC}, \mathrm{C}=\mathrm{O}), 135.5(\mathrm{CH}), 135.1(\mathrm{CH}), 134.5(\mathrm{qC}), 127.1(\mathrm{qC})$, $120.8(\mathrm{CH}), 120.6(\mathrm{qC}), 104.4(\mathrm{qC}), 93.3(\mathrm{qC}), 56.7(\mathrm{CH}), 47.4\left(\mathrm{CH}_{2}\right), 26.3\left(\mathrm{CH}_{2}\right), 23.4\left(\mathrm{CH}_{2}\right), 7.5\left(3 \mathrm{CH}_{3}\right), 4.3(3$ $\mathrm{CH}_{2}$ ).

7-Ethynyl-1,2,3,11a-tetrahydro-5H-benzo[e]pyrrolo[1,2-a][1,4]diazepine-5,11(10H)-dione (35). General method: TBAF (1.4 equiv., 1.0 M in THF, 5\% water) was added dropwise to a solution of the trialkylsilyl protected compound (1.0 equiv.) in THF and the mixture was stirred at RT for 10-15 min. Water (20 mL) was added to the reaction mixture and the crude was extracted with ethyl acetate $(3 \times 30 \mathrm{~mL})$. The organic phase was washed with brine $(25 \mathrm{~mL})$, dried $\left(\mathrm{MgSO}_{4}\right)$, filtered, and concentrated under reduced pressure. The crude product was purified by flash chromatography to give the deprotected product. Compound $\mathbf{3 5}$ was prepared according to the general method using TBAF $(1.68 \mathrm{mmol}, 438 \mathrm{mg}, 1.68 \mathrm{~mL})$, trimethylsilyl protected compound $29(1.2 \mathrm{mmol}, 374 \mathrm{mg})$ and THF $(10 \mathrm{~mL})$. The crude product was purified by flash chromatography $\left(\mathrm{CH}_{2} \mathrm{Cl}_{2}\right.$ /acetone, 9:1) to give compound $35(273 \mathrm{mg}, 95 \%)$ as a white solid; $\mathrm{mp} 236-237{ }^{\circ} \mathrm{C} ; R_{f}=0.2$ $\left(\mathrm{CH}_{2} \mathrm{Cl}_{2}\right.$ /acetone, 9:1). Compound 35 was also prepared according to the general method using TBAF (0.81 $\mathrm{mmol}, 212 \mathrm{mg}, 0.81 \mathrm{~mL})$, triethylsilyl protected compound $30(0.58 \mathrm{mmol}, 205 \mathrm{mg})$ and THF (7 mL) to give compound 35 (125 mg, 90\%). ${ }^{1} \mathrm{H}-\mathrm{NMR}\left(400 \mathrm{MHz}, \mathrm{CDCl}_{3}\right): \delta=8.91(\mathrm{~s}, 1 \mathrm{H}, \mathrm{NH}), 8.15(\mathrm{~d}, J 1.9 \mathrm{~Hz}, 1 \mathrm{H}), 7.58(\mathrm{dd}, J$ 1.9, $8.3 \mathrm{~Hz}, 1 \mathrm{H}), 7.01(\mathrm{~d}, J 8.3 \mathrm{~Hz}, 1 \mathrm{H}), 4.07(\mathrm{~d}, J 7.3 \mathrm{~Hz}, 1 \mathrm{H}, \mathrm{NCH}), 3.88-3.74(\mathrm{~m}, 1 \mathrm{H}, \mathrm{NCHH}), 3.66-3.55(\mathrm{~m}$, $1 \mathrm{H}, \mathrm{NCHH}), 3.10(\mathrm{~s}, 1 \mathrm{H}, \mathrm{C} \equiv \mathrm{CH}), 2.84-2.70(\mathrm{~m}, 1 \mathrm{H}, \mathrm{CHH}), 2.13-1.95\left(\mathrm{~m}, 3 \mathrm{H}, \mathrm{CHH}+\mathrm{CH}_{2}\right) .{ }^{13} \mathrm{C}-\mathrm{NMR}(100 \mathrm{MHz}$, $\left.\mathrm{CDCl}_{3}\right): \delta=171.1(\mathrm{qC}), 164.5(\mathrm{qC}), 135.7(\mathrm{CH}), 135.4(\mathrm{qC}), 135.2(\mathrm{CH}), 127.1(\mathrm{qC}), 121.3(\mathrm{CH}), 119.2(\mathrm{qC}), 82.1$ (qC, $\mathrm{C} \equiv \mathrm{CH}), 78.3(\mathrm{CH}, \mathrm{C} \equiv \mathrm{CH}), 56.8(\mathrm{CH}), 47.5\left(\mathrm{CH}_{2}\right), 26.4\left(\mathrm{CH}_{2}\right), 23.5\left(\mathrm{CH}_{2}\right)$. HRMS (Dual ESI): calc $\mathrm{m} / \mathrm{z}$ for $\mathrm{C}_{14} \mathrm{H}_{12} \mathrm{~N}_{2} \mathrm{O}_{2}: 240.0899[\mathrm{M}], 241.0972[\mathrm{M}+\mathrm{H}]^{+}$; found: $240.0899[\mathrm{M}], 241.0971[\mathrm{M}+\mathrm{H}]^{+}$. FT-IR $\left(\mathrm{cm}^{-1}\right): \mathrm{v}=3232$, 3159, 3050, 2941, 1700, 1620, 1596, 1475, 1438, 1266.

4-Methyl-7-((trimethylsilyl)ethynyl)-3,4-dihydro-1H-benzo[e][1,4]diazepine-2,5-dione (27). Prepared as described for compound 29 using compound 17 (1.7 mmol, $457 \mathrm{mg}), \mathrm{Et}_{3} \mathrm{~N}(25 \mathrm{~mL}), \mathrm{CH}_{3} \mathrm{CN}(20 \mathrm{~mL})$, $\mathrm{PdCl}_{2}\left(\mathrm{PPh}_{3}\right)_{2}(0.17 \mathrm{mmol}, 120 \mathrm{mg}, 10 \mathrm{~mol} \%$ ) and alkyne 23 (3.4 mmol, $334 \mathrm{mg}, 0.47 \mathrm{~mL})$; purified by flash chromatography $\left(\mathrm{CH}_{2} \mathrm{Cl}_{2} / \mathrm{MeOH}, 100: 1\right)$ to give silylalkyne 27 (452 mg, 92\%) as a pale white solid; mp 216-218 ${ }^{\circ} \mathrm{C} ; R_{f}=0.24\left(\mathrm{CH}_{2} \mathrm{Cl}_{2}\right.$ /acetone, 100:5). ${ }^{1} \mathrm{H}-\mathrm{NMR}\left(400 \mathrm{MHz}, \mathrm{CDCl}_{3}\right): \delta=8.94(\mathrm{~s}, 1 \mathrm{H}, \mathrm{NH}), 8.06(\mathrm{~d}, J 1.9 \mathrm{~Hz}, 1 \mathrm{H})$, $7.52(\mathrm{dd}, J$ J 1.9, $\left.8.3 \mathrm{~Hz}, 1 \mathrm{H}), 6.95(\mathrm{~d}, J 8.3 \mathrm{~Hz}, 1 \mathrm{H}), 3.88\left(\mathrm{~s}, 2 \mathrm{H}, \mathrm{CH}_{2}\right), 3.28(\mathrm{~s}, 3 \mathrm{H}, \mathrm{NMe}), 0.24(\mathrm{~s}, 9 \mathrm{H}, \mathrm{SiMe})_{3}\right){ }^{13} \mathrm{C}-$ NMR (100 MHz, CDCl $): \delta=169.9(q C, C=0), 166.5(q C, C=0), 135.7(\mathrm{CH}), 135.5(\mathrm{CH}), 135.3(\mathrm{qC}), 126.6(\mathrm{qC})$, $120.7(\mathrm{qC}), 120.6(\mathrm{CH}), 103.2(\mathrm{qC}), 96.0(\mathrm{qC}), 52.5\left(\mathrm{CH}_{2}\right), 36.7\left(\mathrm{CH}_{3}\right), 0.0\left(3 \mathrm{CH}_{3}\right)$. HRMS (Dual ESI): calc $\mathrm{m} / z$ for $\mathrm{C}_{15} \mathrm{H}_{18} \mathrm{~N}_{2} \mathrm{O}_{2} \mathrm{Si}: 286.1138$ [M], $287.1210[\mathrm{M}+\mathrm{H}]^{+}$; found: 286.1144 [M], $287.1217[\mathrm{M}+\mathrm{H}]^{+}$. FT-IR $\left(\mathrm{cm}^{-1}\right): \mathrm{v}=3219$, 3166, 3035, 2953, 2898, 2156, 1708, 1627, 1607, 1496, 1409, 1360, 1247, 994.

4-Methyl-7-((triethylsilyl)ethynyl)-3,4-dihydro-1H-benzo[e][1,4]diazepine-2,5-dione (28). Prepared as described for compound 29 using compound $17(0.74 \mathrm{mmol}, 200 \mathrm{mg}), \mathrm{Et}_{3} \mathrm{~N}(15 \mathrm{~mL}), \mathrm{CH}_{3} \mathrm{CN}(12 \mathrm{~mL})$, $\mathrm{PdCl}_{2}\left(\mathrm{PPh}_{3}\right)_{2}(37 \mu \mathrm{mol}, 26 \mathrm{mg}, 5 \mathrm{~mol} \%)$ and triethylsilylalkyne 24 (1.49 mmol, $\left.209 \mathrm{mg}, 0.29 \mathrm{~mL}\right)$; purified by 
flash chromatography (EtOAc/PE, 2:3) to give compound 28 (201 mg, 82\%) as a white waxy solid; $R_{f}=0.15$ (EtOAc/PE, 1:1), which was characterized by NMR and used immediately in the next step. ${ }^{1} \mathrm{H}-\mathrm{NMR}(400 \mathrm{MHz}$, $\left.\mathrm{CDCl}_{3}\right): \delta=8.65(\mathrm{~s}, 1 \mathrm{H}, \mathrm{NH}), 8.09(\mathrm{~d}, J 1.9 \mathrm{~Hz}, 1 \mathrm{H}), 7.55(\mathrm{dd}, J 1.9,8.3 \mathrm{~Hz}, 1 \mathrm{H}), 6.95(\mathrm{~d}, J 8.3 \mathrm{~Hz}, 1 \mathrm{H}), 3.90(\mathrm{~s}, 2$ $\mathrm{H}, \mathrm{CH}_{2}$ ), 3.30 (s, $\left.3 \mathrm{H}, \mathrm{Me}\right), 1.05\left(\mathrm{t}, \mathrm{J} 7.9 \mathrm{~Hz}, 9 \mathrm{H}, 3 \times \mathrm{SiCH}_{2} \mathrm{CH}_{3}\right), 0.69$ (q, J 7.9 Hz, $\left.6 \mathrm{H}, 3 \times \mathrm{SiCH}_{2} \mathrm{Me}\right) .{ }^{13} \mathrm{C}-\mathrm{NMR}(100$ $\mathrm{MHz}, \mathrm{CDCl}_{3}$ ): $\delta=169.8(\mathrm{qC}, \mathrm{C}=0), 166.4(\mathrm{qC}, \mathrm{C}=\mathrm{O}), 135.6(\mathrm{CH}), 135.5(\mathrm{CH}), 135.1(\mathrm{qC}), 126.5(\mathrm{qC}), 120.8(\mathrm{qC})$, $120.5(\mathrm{CH}), 104.3(\mathrm{qC}), 93.4(\mathrm{qC}), 52.4\left(\mathrm{CH}_{2}\right), 36.6\left(\mathrm{CH}_{3}\right), 7.4\left(3 \mathrm{CH}_{3}\right), 4.3\left(3 \mathrm{CH}_{2}\right)$.

Ethyl 5-methyl-6-oxo-8-((triethylsilyl)ethynyl)-5,6-dihydro-4H-benzo[f]imidazo[1,5-a][1,4]diazepine-3carboxylate (26). Prepared as described for compound 29 using bromo-compound 21 (0.41 mmol, $150 \mathrm{mg}$ ), $\mathrm{Et}_{3} \mathrm{~N}(10 \mathrm{~mL}), \mathrm{CH}_{3} \mathrm{CN}(8 \mathrm{~mL}), \mathrm{PdCl}_{2}\left(\mathrm{PPh}_{3}\right)_{2}(29 \mathrm{mg}, 41 \mu \mathrm{mol}, 10 \mathrm{~mol} \%)$ and alkyne 24 (0.82 mmol, $116 \mathrm{mg}, 0.15$ $\mathrm{mL})$; purified by flash chromatography $\left(\mathrm{CH}_{2} \mathrm{Cl}_{2}\right.$ /acetone, 100:4) to give compound 26 (167 $\left.\mathrm{mg}, 96 \%\right)$ as a pale brown oil; $R_{f}=0.3\left(\mathrm{CH}_{2} \mathrm{Cl}_{2}\right.$ /acetone, 100:8), which was characterized by NMR and used immediately in the next step (see supplementary information). ${ }^{1} \mathrm{H}-\mathrm{NMR}\left(400 \mathrm{MHz}, \mathrm{CDCl}_{3}\right): \delta=8.18(\mathrm{~d}, J 1.8 \mathrm{~Hz}, 1 \mathrm{H}), 7.93(\mathrm{~s}, 1 \mathrm{H}), 7.70$ (dd, J 1.8, 8.3 Hz, $1 \mathrm{H}), 7.39(\mathrm{~d}, J 8.3 \mathrm{~Hz}, 1 \mathrm{H}), 5.22(\mathrm{bm}, 1 \mathrm{H}, \mathrm{OCHH}), 4.55-4.28\left(\mathrm{~m}, 3 \mathrm{H}, \mathrm{OCHH}+\mathrm{NCH}_{2}\right), 3.26(\mathrm{~s}$, $3 \mathrm{H}, \mathrm{NMe}), 1.46\left(\mathrm{t}, J 7.1 \mathrm{~Hz}, 3 \mathrm{H}, \mathrm{OCH}_{2} \mathrm{CH}_{3}\right), 1.06\left(\mathrm{t}, J 7.9 \mathrm{~Hz}, 9 \mathrm{H}, 3 \times \mathrm{SiCH}_{2} \mathrm{CH}_{3}\right), 0.70(\mathrm{q}, J 7.9 \mathrm{~Hz}, 6 \mathrm{H}, 3 \times$ $\left.\mathrm{SiCH}_{2} \mathrm{Me}\right)$.

${ }^{13} \mathrm{C}-\mathrm{NMR}\left(100 \mathrm{MHz}, \mathrm{CDCl}_{3}\right): \delta=165.8(\mathrm{qC}), 162.8(\mathrm{qC}), 136.3(\mathrm{CH}), 135.6(\mathrm{CH}), 135.4(\mathrm{qC}), 134.8(\mathrm{CH}), 131.2$ $(q C), 129.1(q C), 128.7(q C), 124.3(q C), 121.8(\mathrm{CH}), 103.5(q C), 95.5(q C), 61.1\left(\mathrm{CH}_{2}\right), 42.3\left(\mathrm{CH}_{2}\right), 35.9\left(\mathrm{CH}_{3}\right)$, $14.3\left(\mathrm{CH}_{3}\right), 7.4\left(3 \mathrm{CH}_{3}\right), 4.2\left(3 \mathrm{CH}_{2}\right)$.

General procedure for azide to alkyne cycloadditions. To a suspension of 4 '-azidoisoflavone (1.0 equiv.) and the corresponding alkyne (1.0 equiv.) in a $\mathrm{H}_{2} \mathrm{O} / \mathrm{t}$ - $\mathrm{BuOH}$ mixture (2:1 ratio), sodium ascorbate (0.1-0.2 equiv.) was added, followed by $\mathrm{CuSO}_{4} \cdot 5 \mathrm{H}_{2} \mathrm{O}$ (0.02-0.05 equiv.). After the resulting mixture was stirred rapidly overnight at $100{ }^{\circ} \mathrm{C}$, the end of reaction was confirmed by TLC and the mixture was diluted with $10 \mathrm{~mL}$ of water and cooled in ice. The precipitate was collected by filtration, washed with cold water $(10 \mathrm{~mL}), \mathrm{CH}_{2} \mathrm{Cl}_{2}(10$ $\mathrm{mL})$, and $\mathrm{CH}_{3} \mathrm{OH}(10 \mathrm{~mL})$ and dried under vacuum suction to give the desired hybrid.

7-(1-(4-(7-Hydroxy-4-oxo-4H-chromen-3-yl)phenyl)-1H-1,2,3-triazol-4-yl)-1,2,3,11a-tetrahydro-5H-benzo[e] pyrrolo[1,2-a][1,4]diazepine-5,11(10H)-dione (36). Prepared according to the general procedure using azido

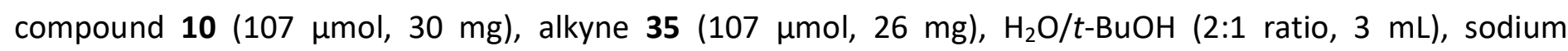
ascorbate $\left(21.5 \mu \mathrm{mol}, 4.5 \mathrm{mg}, 0.2\right.$ equiv.) and $\mathrm{CuSO}_{4} \cdot 5 \mathrm{H}_{2} \mathrm{O}(5.5 \mu \mathrm{mol}, 1.5 \mathrm{mg}, 0.05$ equiv.); workup gave the product 36 (35 mg, 63\%) as a pale brown solid; $\mathrm{mp}>300{ }^{\circ} \mathrm{C} ; R_{f}=0.4\left(\mathrm{CH}_{2} \mathrm{Cl}_{2} / \mathrm{CH}_{3} \mathrm{OH}, 95: 5\right) .{ }^{1} \mathrm{H}-\mathrm{NMR}(400 \mathrm{MHz}$, $d_{6}$-DMSO, $d_{6}$-acetone): $\delta=10.87(\mathrm{~s}, 1 \mathrm{H}, \mathrm{OH}), 10.62(\mathrm{~s}, 1 \mathrm{H}, \mathrm{NH}), 9.43(\mathrm{~s}, 1 \mathrm{H}), 8.54(\mathrm{~s}, 1 \mathrm{H}), 8.36(\mathrm{~d}, J 2.0 \mathrm{~Hz}, 1$ H), 8.07 (dd, J 2.0, $8.4 \mathrm{~Hz}, 1 \mathrm{H}), 8.02(\mathrm{~d}, J 8.6 \mathrm{~Hz}, 2 \mathrm{H}), 8.00(\mathrm{~d}, J 8.7 \mathrm{~Hz}, 1 \mathrm{H}), 7.84(\mathrm{~d}, J 8.6 \mathrm{~Hz}, 2 \mathrm{H}), 7.24(\mathrm{~d}, J 8.4$ $\mathrm{Hz}, 1 \mathrm{H}), 6.96(\mathrm{dd}, J$ 2.1, 8.7 Hz, $1 \mathrm{H}), 6.90(\mathrm{~d}, J 2.1 \mathrm{~Hz}, 1 \mathrm{H}), 4.20(\mathrm{~d}, J 7.9 \mathrm{~Hz}, 1 \mathrm{H}, \mathrm{NCH}), 3.66-3.58(\mathrm{~m}, 1 \mathrm{H}$, $\mathrm{NCHH}), 3.52-3.44(\mathrm{~m}, 1 \mathrm{H}, \mathrm{NCHH}), 2.01-1.76\left(\mathrm{~m}, 4 \mathrm{H}, 2 \times \mathrm{CH}_{2}\right) .{ }^{13} \mathrm{C}-\mathrm{NMR}\left(100 \mathrm{MHz}, d_{6}\right.$-DMSO, $d_{6}$-acetone): $\delta$ $=174.7(q C), 171.0(q C), 164.7(q C), 163.2(q C), 157.9(q C), 154.8(\mathrm{CH}), 146.8(q C), 136.6(q C), 136.3(q C), 133.0$ $(q C), 130.7(2 \mathrm{CH}), 129.2(\mathrm{CH}), 127.8(\mathrm{CH}), 127.6(\mathrm{CH}), 127.5(\mathrm{qC}), 126.4(\mathrm{qC}), 122.8(\mathrm{qC}), 122.5(\mathrm{CH}), 120.0(3$ $\mathrm{CH}), 117.0(\mathrm{qC}), 115.9(\mathrm{CH}), 102.7(\mathrm{CH}), 56.7(\mathrm{CH}), 47.4\left(\mathrm{CH}_{2}\right), 26.2\left(\mathrm{CH}_{2}\right), 23.5\left(\mathrm{CH}_{2}\right)$. HRMS (Dual ESI): calc $\mathrm{m} / \mathrm{z}$ for $\mathrm{C}_{29} \mathrm{H}_{21} \mathrm{~N}_{5} \mathrm{O}_{5}: 519.1543[\mathrm{M}], 520.1615[\mathrm{M}+\mathrm{H}]^{+}$; found: $519.1542[\mathrm{M}], 520.1617[\mathrm{M}+\mathrm{H}]^{+}$. FT-IR $\left(\mathrm{cm}^{-1}\right): \mathrm{U}=$ 3204, 3140, 3085, 2980, 2881, 1693, 1620, 1604, 1567, 1441, 1378, 1259, 1040.

7-(1-(4-(7-Hydroxy-4-oxo-4H-chromen-3-yl)phenyl)-1H-1,2,3-triazol-4-yl)-4-methyl-3,4-dihydro-1H-benzo[e] [1,4]diazepine-2,5-dione (37). Prepared according to the general procedure using azido compound 10 (107 $\mu \mathrm{mol}, 30 \mathrm{mg})$, alkyne 32 (107 $\mu \mathrm{mol}, 23 \mathrm{mg}), \mathrm{H}_{2} \mathrm{O} / \mathrm{t}$ - $\mathrm{BuOH}(2: 1$ ratio, $3 \mathrm{~mL})$, sodium ascorbate $(21.5 \mu \mathrm{mol}, 4.5$ $\mathrm{mg}, 0.2$ equiv.) and $\mathrm{CuSO}_{4} \cdot 5 \mathrm{H}_{2} \mathrm{O}(5.5 \mu \mathrm{mol}, 1.5 \mathrm{mg}, 0.05$ equiv.); workup gave product 37 (34 mg, 64\%) as a brown solid; $\mathrm{mp}>300{ }^{\circ} \mathrm{C} ; R_{f}=0.4\left(\mathrm{CH}_{2} \mathrm{Cl}_{2} / \mathrm{CH}_{3} \mathrm{OH}, 95: 5\right) .{ }^{1} \mathrm{H}-\mathrm{NMR}\left(400 \mathrm{MHz}, d_{6}\right.$-DMSO, $d_{6}$-acetone): $\delta=10.88$ 
(s, $1 \mathrm{H}, \mathrm{OH}), 10.59(\mathrm{~s}, 1 \mathrm{H}, \mathrm{NH}), 9.43(\mathrm{~s}, 1 \mathrm{H}), 8.55(\mathrm{~s}, 1 \mathrm{H}), 8.32(\mathrm{~s}, 1 \mathrm{H}), 8.08-7.99(\mathrm{~m}, 4 \mathrm{H}), 7.84(\mathrm{~d}, J 8.3 \mathrm{~Hz}, 2$ H), $7.22(\mathrm{~d}, J 8.4 \mathrm{~Hz}, 1 \mathrm{H}), 6.96(\operatorname{app~d}, J 8.9 \mathrm{~Hz}, 1 \mathrm{H}), 6.91(\mathrm{app} \mathrm{s}, 1 \mathrm{H}), 3.91\left(\mathrm{~s}, 2 \mathrm{H}, \mathrm{CH}_{2}\right), 3.15(\mathrm{~s}, 3 \mathrm{H}, \mathrm{Me}) .{ }^{13} \mathrm{C}-$ NMR (100 MHz, $d_{6}$-DMSO, $d_{6}$-acetone): $\delta=174.7$ (qC), $170.1(q C), 166.7$ (qC), 163.2 (qC), 157.9 (qC), 154.8 $(\mathrm{CH}), 146.8(q C), 137.2(q C), 136.3(q C), 133.0(q C), 130.7(2 \mathrm{CH}), 129.1(\mathrm{CH}), 128.2(\mathrm{CH}), 127.8(\mathrm{CH}), 127.1(q C)$, $126.4(\mathrm{qC}), 122.8(\mathrm{qC}), 121.9(\mathrm{CH}), 120.0(3 \mathrm{CH}), 117.0(\mathrm{qC}), 115.8(\mathrm{CH}), 102.7(\mathrm{CH}), 52.7\left(\mathrm{CH}_{2}\right), 36.4\left(\mathrm{CH}_{3}\right)$. HRMS (Dual ESI): calc $m / z$ for $\mathrm{C}_{27} \mathrm{H}_{19} \mathrm{~N}_{5} \mathrm{O}_{5}$ : 493.1386 [M], 494.1459 [M+H] ${ }^{+}$; found: 493.1389 [M], 494.1460 $[\mathrm{M}+\mathrm{H}]^{+} . \mathrm{T}-\mathrm{IR}\left(\mathrm{cm}^{-1}\right): \mathrm{v}=3190,3108,3080,2935,1704,1621,1581,1486,1372,1260,1034$.

Ethyl 7-(1-(4-(7-hydroxy-4-oxo-4H-chromen-3-yl)phenyl)-1H-1,2,3-triazol-4-yl)-9-oxo-11,12,13,13atetrahydro-9H-benzo[e]imidazo[5,1-c]pyrrolo[1,2-a][1,4]diazepine-1-carboxylate (38). Prepared according to the general procedure using azido compound 10 (107 $\mu \mathrm{mol}, 30 \mathrm{mg}$ ), alkyne 34 (107 $\mu \mathrm{mol}, 36 \mathrm{mg}), \mathrm{H}_{2} \mathrm{O} / \mathrm{t}-\mathrm{BuOH}$ (2:1 ratio, $3 \mathrm{~mL})$, sodium ascorbate $\left(21.5 \mu \mathrm{mol}, 4.5 \mathrm{mg}, 0.2\right.$ equiv.) and $\mathrm{CuSO}_{4} \cdot 5 \mathrm{H}_{2} \mathrm{O}(5.5 \mu \mathrm{mol}, 1.5 \mathrm{mg}, 0.05$ equiv.); workup gave product 38 (40 mg, 60\%) as a brown solid; $\mathrm{mp} 277^{\circ} \mathrm{C}$ (decomp.); $R_{f}=0.4\left(\mathrm{CH}_{2} \mathrm{Cl}_{2} / \mathrm{CH}_{3} \mathrm{OH}\right.$, 95:5). ${ }^{1} \mathrm{H}-\mathrm{NMR}\left(400 \mathrm{MHz}, d_{6}\right.$-DMSO): $\delta=10.90$ (br s, $\left.1 \mathrm{H}, \mathrm{OH}\right), 9.62(\mathrm{~s}, 1 \mathrm{H}), 8.57(\mathrm{~s}, 1 \mathrm{H}), 8.53(\mathrm{~s}, 1 \mathrm{H}), 8.32(\mathrm{~s}, 1$ H), $8.30(\mathrm{~d}, J 8.6 \mathrm{~Hz}, 1 \mathrm{H}), 8.06(\mathrm{~d}, J 7.8 \mathrm{~Hz}, 2 \mathrm{H}), 8.02(\mathrm{~d}, J 7.9 \mathrm{~Hz}, 1 \mathrm{H}), 7.91-7.82(\mathrm{~m}, 3 \mathrm{H}), 6.99(\mathrm{~d}, J 8.4 \mathrm{~Hz}, 1$ $\mathrm{H}), 6.93(\mathrm{~s}, 1 \mathrm{H}), 5.1-4.9(\mathrm{bm}, 1 \mathrm{H}, \mathrm{NCH}), 4.4-4.2\left(\mathrm{bm}, 2 \mathrm{H}, \mathrm{NCH}_{2}\right), 3.65-3.64(\mathrm{~m}, 1 \mathrm{H}, \mathrm{CHH}), 3.50-3.48(\mathrm{~m}, 1$ $\mathrm{H}, \mathrm{CHH}), 3.21-3.17(\mathrm{~m}, 1 \mathrm{H}, \mathrm{CHH}), 2.23-2.09\left(\mathrm{~m}, 3 \mathrm{H}, \mathrm{CHH}+\mathrm{CH}_{2}\right), 1.44-1.24(\mathrm{~m}, 3 \mathrm{H}, \mathrm{Me}) .{ }^{13} \mathrm{C}-\mathrm{NMR}(100$ $\mathrm{MHz}, d_{6}$-DMSO): $\delta=174.6(\mathrm{qC}), 163.3(\mathrm{qC}), 163.2(\mathrm{qC}), 157.9(\mathrm{qC}), 155.9(\mathrm{qC}), 154.8(\mathrm{CH}), 146.1(\mathrm{qC}), 139.7$ $(q C), 136.2(q C), 133.1(q C), 130.7(2 \mathrm{CH}), 130.5(q C), 130.0(q C), 129.4(\mathrm{CH}), 127.8(2 \mathrm{CH}), 125.4(\mathrm{CH}), 122.7$ (qC), $122.0(\mathrm{qC}), 120.9(\mathrm{CH}), 120.0(3 \mathrm{CH}), 117.0(\mathrm{qC}), 115.8(\mathrm{CH}), 102.6(\mathrm{CH}), 61.0\left(\mathrm{CH}_{2}\right), 46.7\left(\mathrm{CH}_{2}\right), 28.2\left(\mathrm{CH}_{2}\right)$, $24.4\left(\mathrm{CH}_{2}\right), 14.6\left(\mathrm{CH}_{3}\right)$. HRMS (Dual ESI): calc $\mathrm{m} / z$ for $\mathrm{C}_{34} \mathrm{H}_{26} \mathrm{~N}_{6} \mathrm{O}_{6}: 614.1914$ [M], 615.1987 [M+H] ${ }^{+}$; found: $614.1908[\mathrm{M}], 615.1978[\mathrm{M}+\mathrm{H}]^{+}$. FT-IR $\left(\mathrm{cm}^{-1}\right): \mathrm{u}=3201,3126,3077,2978,2897,1714,1625,1610,1574,1451$, 1370, 1261, 1190, 1037.

Ethyl 8-(1-(4-(7-hydroxy-4-oxo-4H-chromen-3-yl)phenyl)-1H-1,2,3-triazol-4-yl)-5-methyl-6-oxo-5,6-dihydro4H-benzo[f]imidazo[1,5-a][1,4]diazepine-3-carboxylate (39). Prepared according to the general procedure

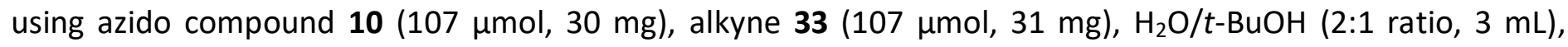
sodium ascorbate $\left(21.5 \mu \mathrm{mol}, 4.5 \mathrm{mg}, 0.2\right.$ equiv.) and $\mathrm{CuSO}_{4} \cdot 5 \mathrm{H}_{2} \mathrm{O}(5.5 \mu \mathrm{mol}, 1.5 \mathrm{mg}, 0.05$ equiv.); workup gave alkyne 39 (33 mg, 56\%) as a pale brown solid; $\mathrm{mp} 277{ }^{\circ} \mathrm{C}$ (decomp.); $R_{f}=0.4\left(\mathrm{CH}_{2} \mathrm{Cl}_{2} / \mathrm{CH}_{3} \mathrm{OH}, 95: 5\right)$.

${ }^{1} \mathrm{H}-\mathrm{NMR}\left(400 \mathrm{MHz}, d_{6}\right.$-DMSO, $d_{6}$-acetone): $\delta=10.88$ (br s, $\left.1 \mathrm{H}, \mathrm{OH}\right), 9.58(\mathrm{~s}, 1 \mathrm{H}), 8.55(\mathrm{~s}, 1 \mathrm{H}), 8.47(\mathrm{~s}, 1 \mathrm{H})$, $8.27(\mathrm{~d}, J 8.0 \mathrm{~Hz}, 2 \mathrm{H}), 8.09-7.97(\mathrm{~m}, 3 \mathrm{H}), 7.93-7.81(\mathrm{~m}, 3 \mathrm{H}), 7.03-6.86(\mathrm{~m}, 2 \mathrm{H}), 5.1-4.9(\mathrm{bm}, 1 \mathrm{H}, \mathrm{CHH})$, $4.7-4.5(\mathrm{bm}, 1 \mathrm{H}, \mathrm{CHH}), 4.40-4.20\left(\mathrm{~m}, 2 \mathrm{H}, \mathrm{CH}_{2}\right), 3.13(\mathrm{~s}, 3 \mathrm{H}, \mathrm{Me}), 1.42-1.30(\mathrm{~m}, 3 \mathrm{H}, \mathrm{Me})$.

${ }^{13} \mathrm{C}$-NMR (100 MHz, $d_{6}$-DMSO, $d_{6}$-acetone): $\delta=174.7$ (qC), 165.9 (qC), 163.3 (qC), 158.0 (qC), 155.9 (qC), 154.9 $(\mathrm{CH}), 147.1(q C), 146.1(q C), 139.7(q C), 136.2(q C), 133.1(q C), 130.7(2 \mathrm{CH}), 130.4(q C), 129.8(q C), 129.4(\mathrm{CH})$, $128.7(\mathrm{CH}), 127.8(\mathrm{CH}), 124.2(\mathrm{CH}), 122.7(\mathrm{qC}), 122.0(\mathrm{qC}), 120.9(\mathrm{CH}), 120.0(3 \mathrm{CH}), 117.0(\mathrm{qC}), 115.9(\mathrm{CH})$, $102.7(\mathrm{CH}), 60.6\left(\mathrm{CH}_{2}\right), 35.6\left(\mathrm{CH}_{3}\right), 14.7\left(\mathrm{CH}_{3}\right)$. HRMS (Dual ESI): calc $\mathrm{m} / z$ for $\mathrm{C}_{32} \mathrm{H}_{24} \mathrm{~N}_{6} \mathrm{O}_{6}: 588.1757$ [M], $589.1830[\mathrm{M}+\mathrm{H}]^{+}$; found: $588.1752[\mathrm{M}], 589.1824[\mathrm{M}+\mathrm{H}]^{+} . \mathrm{FT}-\mathrm{IR}\left(\mathrm{cm}^{-1}\right): \mathrm{v}=3321,3210,3115,3078,2980$, $1702,1624,1573,1500,1457,1377,1258,1194,1035$.

\section{3-(4-(4-(5,11-Dioxo-2,3,5,10,11,11a-hexahydro-1H-benzo[e]pyrrolo[1,2-a][1,4]diazepin-7-yl)-1H-1,2,3-}

triazol-1-yl)phenyl)-4-oxo-4H-chromen-7-yl acetate (40). Prepared according to the general procedure using

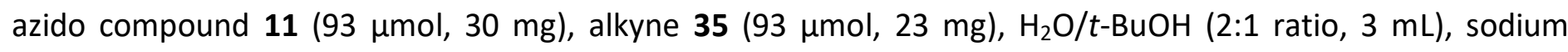
ascorbate (18.7 $\mu \mathrm{mol}, 4 \mathrm{mg}, 0.2$ equiv.) and $\mathrm{CuSO}_{4} \cdot 5 \mathrm{H}_{2} \mathrm{O}(4.7 \mu \mathrm{mol}, 1.5 \mathrm{mg}, 0.05$ equiv.); workup gave product 40 (48 mg, 91\%) as a pale brown solid; $\mathrm{mp}>300{ }^{\circ} \mathrm{C}$. ${ }^{13} \mathrm{C}-\mathrm{NMR}$ data could not be collected due to poor solubility. ${ }^{1} \mathrm{H}-\mathrm{NMR}\left(400 \mathrm{MHz}, d_{6}\right.$-DMSO): $\delta=10.65(\mathrm{~s}, 1 \mathrm{H}), 9.47(\mathrm{~s}, 1 \mathrm{H}), 8.72(\mathrm{~s}, 1 \mathrm{H}), 8.38(\mathrm{~d}, J 2.1 \mathrm{~Hz}, 1 \mathrm{H}), 8.22(\mathrm{~d}, J 8.7$ $\mathrm{Hz}, 1 \mathrm{H}), 8.13-8.05(\mathrm{~m}, 3 \mathrm{H}), 7.89(\mathrm{~d}, J 8.6 \mathrm{~Hz}, 2 \mathrm{H}), 7.64(\mathrm{~d}, J 2.1 \mathrm{~Hz}, 1 \mathrm{H}), 7.36(\mathrm{dd}, J 2.1,8.7 \mathrm{~Hz}, 1 \mathrm{H}), 7.27(\mathrm{~d}, J$ $8.5 \mathrm{~Hz}, 1 \mathrm{H}), 4.23(\mathrm{~d}, J 7.9 \mathrm{~Hz}, 1 \mathrm{H}, \mathrm{NCH}), 3.70-3.60(\mathrm{~m}, 1 \mathrm{H}, \mathrm{NCHH}), 3.55-3.45(\mathrm{~m}, 1 \mathrm{H}, \mathrm{NCHH}), 2.36(\mathrm{~s}, 3 \mathrm{H}$, 
Me), 2.05 - $1.75\left(\mathrm{~m}, 4 \mathrm{H}, 2 \times \mathrm{CH}_{2}\right.$ ). HRMS (Dual ESI): calc $\mathrm{m} / z$ for $\mathrm{C}_{31} \mathrm{H}_{23} \mathrm{~N}_{5} \mathrm{O}_{6}: 561.1648$ [M], 562.1721 [M+H] ; found: $561.1652[\mathrm{M}], 562.1724[\mathrm{M}+\mathrm{H}]^{+}$. FT-IR $\left(\mathrm{cm}^{-1}\right): v=3213,3149,3078,2980,2884,1750,1682,1615$, 1567, 1520, 1484, 1434, 1371, 1208, 1181, 1098, 1034.

\section{3-(4-(4-(4-Methyl-2,5-dioxo-2,3,4,5-tetrahydro-1H-benzo[e][1,4]diazepin-7-yl)-1H-1,2,3-triazol-1-yl)phenyl)-}

4-oxo-4H-chromen-7-yl acetate (41). Prepared according to the general procedure using azido compound $\mathbf{1 1}$ (93 $\mu \mathrm{mol}, 30 \mathrm{mg})$, alkyne 32 (93 $\mu \mathrm{mol}, 20 \mathrm{mg}), \mathrm{H}_{2} \mathrm{O} / \mathrm{t}$-BuOH (2:1 ratio, $3 \mathrm{~mL}$ ), sodium ascorbate $(18.7 \mu \mathrm{mol}, 4$ $\mathrm{mg}, 0.2$ equiv.) and $\mathrm{CuSO}_{4} \cdot 5 \mathrm{H}_{2} \mathrm{O}(4.7 \mu \mathrm{mol}, 1.5 \mathrm{mg}, 0.05$ equiv.); workup gave compound 41 (42 mg, $84 \%)$ as a pale brown solid; $\mathrm{mp}>300{ }^{\circ} \mathrm{C} .{ }^{13} \mathrm{C}-\mathrm{NMR}$ data could not be collected due to poor solubility ${ }^{1} \mathrm{H}-\mathrm{NMR}(400 \mathrm{MHz}$, $d_{6}$-DMSO): $\delta=10.59$ (s, $\left.1 \mathrm{H}\right), 9.44(\mathrm{~s}, 1 \mathrm{H}), 8.70(\mathrm{~s}, 1 \mathrm{H}), 8.32$ (app s, $\left.1 \mathrm{H}\right), 8.20$ (d, J $\left.8.6 \mathrm{~Hz}, 1 \mathrm{H}\right), 8.11-8.00$ (m, $3 \mathrm{H}), 7.87$ (d, J $8.2 \mathrm{~Hz}, 2 \mathrm{H}), 7.61(\operatorname{app~s}, 1 \mathrm{H}), 7.34$ (app d, J $8.9 \mathrm{~Hz}, 1 \mathrm{H}), 7.22$ (app d, J 8.3 Hz, $1 \mathrm{H}), 3.91(\mathrm{~s}, 2 \mathrm{H}$, $\mathrm{CH}_{2}$ ), 3.15 (s, $3 \mathrm{H}, \mathrm{Me}$ ), 2.33 (s, $3 \mathrm{H}, \mathrm{Me}$ ). HRMS (Dual ESI): calc $\mathrm{m} / \mathrm{z}$ for $\mathrm{C}_{29} \mathrm{H}_{21} \mathrm{~N}_{5} \mathrm{O}_{6}: 535.1492$ [M], 536.1565 $[\mathrm{M}+\mathrm{H}]^{+}$; found: $535.1507[\mathrm{M}], 536.1577[\mathrm{M}+\mathrm{H}]^{+}$. FT-IR $\left(\mathrm{cm}^{-1}\right): \mathrm{v}=3232,3148,3077,2980,2875,1748,1695$, 1633, 1574, 1486, 1435, 1362, 1222, 1183, 1033.

Ethyl 7-(1-(4-(7-Acetoxy-4-oxo-4H-chromen-3-yl)phenyl)-1H-1,2,3-triazol-4-yl)-9-oxo-11,12,13,13atetrahydro-9H-benzo[e]imidazo[5,1-c]pyrrolo[1,2-a][1,4]diazepine-1-carboxylate (42). Prepared according to the general procedure using azido compound $\mathbf{1 1}(93 \mu \mathrm{mol}, 30 \mathrm{mg})$, alkyne 34 (93 $\mu \mathrm{mol}, 31 \mathrm{mg}), \mathrm{H}_{2} \mathrm{O} / \mathrm{t}-\mathrm{BuOH}$ (2:1 ratio, $3 \mathrm{~mL})$, sodium ascorbate $\left(18.7 \mu \mathrm{mol}, 4 \mathrm{mg}, 0.2\right.$ equiv.) and $\mathrm{CuSO}_{4} \cdot 5 \mathrm{H}_{2} \mathrm{O}(4.7 \mu \mathrm{mol}, 1.5 \mathrm{mg}, 0.05$ equiv.); workup gave compound 42 (50 mg, 82\%) as a brown solid; mp $262{ }^{\circ} \mathrm{C}$ (decomp.). ${ }^{13} \mathrm{C}$-NMR data could not be collected due to poor solubility. ${ }^{1} \mathrm{H}-\mathrm{NMR}\left(400 \mathrm{MHz}, d_{6}\right.$-DMSO): $\delta=9.63(\mathrm{~s}, 1 \mathrm{H}), 8.72(\mathrm{~s}, 1 \mathrm{H}), 8.52(\mathrm{~d}, J$ $1.9 \mathrm{~Hz}, 1 \mathrm{H}), 8.30$ (br s, $1 \mathrm{H}), 8.29(\mathrm{dd}, J 1.9,8.0 \mathrm{~Hz}, 1 \mathrm{H}), 8.21(\mathrm{~d}, J 8.7 \mathrm{~Hz}, 1 \mathrm{H}), 8.08(\mathrm{~d}, J 8.6 \mathrm{~Hz}, 2 \mathrm{H}), 7.90-7.85$ $(\mathrm{m}, 3 \mathrm{H}), 7.63(\mathrm{~d}, J 2.1 \mathrm{~Hz}, 1 \mathrm{H}), 7.35(\mathrm{dd}, J 2.1,8.7 \mathrm{~Hz}, 1 \mathrm{H}), 4.97(\mathrm{~d}, J 8.0 \mathrm{~Hz}, 1 \mathrm{H}, \mathrm{NCH}), 4.29(\mathrm{q}, J 7.0 \mathrm{~Hz}, 2 \mathrm{H}$, $\left.\mathrm{CH}_{2} \mathrm{Me}\right), 3.66-3.62(\mathrm{~m}, 1 \mathrm{H}, \mathrm{NCHH}), 3.48-3.44(\mathrm{~m}, 1 \mathrm{H}, \mathrm{NCHH}), 3.22-3.16(\mathrm{~m}, 1 \mathrm{H}, \mathrm{CHH}), 2.34(\mathrm{~s}, 3 \mathrm{H}, \mathrm{Me})$, $2.21-2.07\left(\mathrm{~m}, 3 \mathrm{H}, \mathrm{CHH}+\mathrm{CH}_{2}\right.$ ), 1.30 (t, J $7.0 \mathrm{~Hz}, 3 \mathrm{H}$, Me). HRMS (Dual ESI): calc $m / z$ for $\mathrm{C}_{36} \mathrm{H}_{28} \mathrm{~N}_{6} \mathrm{O}_{7}: 656.2019$ $[\mathrm{M}], 657.2092[\mathrm{M}+\mathrm{H}]^{+}$; found: $656.2008[\mathrm{M}], 657.2081[\mathrm{M}+\mathrm{H}]^{+} . \mathrm{FT}-\mathrm{IR}\left(\mathrm{cm}^{-1}\right): \mathrm{u}=3078,2980,2890,1770,1713$, 1639, 1610, 1557, 1519, 1437, 1366, 1181, 1103, 1036.

Ethyl 8-(1-(4-(7-acetoxy-4-oxo-4H-chromen-3-yl)phenyl)-1H-1,2,3-triazol-4-yl)-5-methyl-6-oxo-5,6-dihydro4H-benzo[f]imidazo[1,5-a][1,4]diazepine-3-carboxylate (43). Prepared according to the general procedure

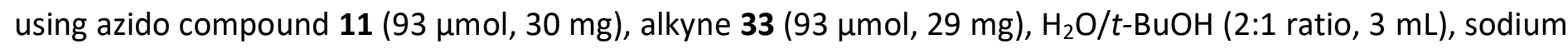
ascorbate (18.7 $\mu \mathrm{mol}, 4 \mathrm{mg}, 0.2$ equiv.) and $\mathrm{CuSO}_{4} \cdot 5 \mathrm{H}_{2} \mathrm{O}\left(4.7 \mu \mathrm{mol}, 1.5 \mathrm{mg}, 0.05\right.$ equiv.), overnight at $100{ }^{\circ} \mathrm{C}$; workup gave compound 43 (42 mg, 71\%) as a brown solid; $\mathrm{mp} 274{ }^{\circ} \mathrm{C}$ (decomp.). ${ }^{13} \mathrm{C}-\mathrm{NMR}$ data could not be collected due to poor solubility.

${ }^{1} \mathrm{H}-\mathrm{NMR}\left(400 \mathrm{MHz}, d_{6}\right.$-DMSO): $\delta=9.60(\mathrm{~s}, 1 \mathrm{H}), 8.71(\mathrm{~s}, 1 \mathrm{H}), 8.48(\mathrm{app} \mathrm{d}, J 1.2 \mathrm{~Hz}, 2 \mathrm{H}), 8.28$ (app dd, J 1.2, 8.0 $\mathrm{Hz}, 1 \mathrm{H}), 8.21(\mathrm{~d}, J 8.4 \mathrm{~Hz}, 1 \mathrm{H}), 8.06(\mathrm{~d}, J 8.6 \mathrm{~Hz}, 2 \mathrm{H}), 7.95-7.85(\mathrm{~m}, 3 \mathrm{H}), 7.62(\mathrm{~d}, J 2.0 \mathrm{~Hz}, 1 \mathrm{H}), 7.35$ (dd, J 2.0, $8.4 \mathrm{~Hz}, 1 \mathrm{H}), 5.1-4.9(\mathrm{bm}, 1 \mathrm{H}, \mathrm{CHH}), 4.7-4.5(\mathrm{bm}, 1 \mathrm{H}, \mathrm{CHH}), 4.41-4.23\left(\mathrm{~m}, 2 \mathrm{H}, \mathrm{CH}_{2}\right), 3.14(\mathrm{~s}, 3 \mathrm{H}, \mathrm{NMe})$, 2.34 (s, $3 \mathrm{H}, \mathrm{Me}$ ), $1.39-1.28$ (m, $3 \mathrm{H}, \mathrm{Me}$ ). HRMS (Dual ESI): calc $m / z$ for $\mathrm{C}_{34} \mathrm{H}_{26} \mathrm{~N}_{6} \mathrm{O}_{7}: 630.1863$ [M], 631.1936 $[\mathrm{M}+\mathrm{H}]^{+}$; found: $630.1870[\mathrm{M}], 631.1943[\mathrm{M}+\mathrm{H}]^{+}$. FT-IR $\left(\mathrm{cm}^{-1}\right): \mathrm{v}=3115,3062,2981,1752,1731,1661,1638$, $1602,1573,1495,1438,1372,1212,1157,1037$.

\section{Acknowledgements}

We thank the University of Huddersfield for a PhD studentship (to GM), Dr Neil McLay (NMR), Dr Jack Blackburn and Dr Sean Ward (HRMS) for analytical support. 


\section{Supplementary Material}

Methods and characterization data for the synthesis of known compounds 8, 9, 16, 18, 22, 31, 34, 15, 17, 32, 21, 25 and 33, full details of the biological methodology, and copies of NMR spectra for previously unreported compounds can be found in the Supplementary Material. This material can be accessed using the link "Supplementary Material" in the journal issue contents page.

\section{References}

1. Al-Maharik, N. Nat. Prod. Rep. 2019, 36, 1156.

http://doi.org/10.1039/c8np00069g

2. Křížová, L., Dadáková, K.; Kašparovská, J.; Kašparovský, T. Molecules 2019, 24, 1076. http://doi.org/10.3390/molecules24061076

3. Yu, J.; Bi, X.; Yu, B.; Chen, D. Nutrients, 2016, 8, 361. http://doi.org/10.3390/nu8060361

4. Occhiuto, F.; Palumbo, D. R.; Samperi, S.; Zangla, G.; Pino, A.; De Pasquale, R.; Circosta, C. Phytother. Res. 2009, 23, 192. http://doi.org/10.1002/ptr.2584

5. Xiao, H.; Qin, X.; Wan, J.; Li, R. Med. Sci. Monit. 2019, 25, 4273. http://doi.org/10.12659/MSM.916662

6. Wei, J.; Yang, F.; Gong, C.; Shi, X.; Wang, G. J. Biochem. Mol. Toxicol. 2019, 33, e22319. http://doi.org/10.1002/jbt.22319

7. Ko, Y.-H.; Kim, S. Y.; Lee, S.-Y.; Jang, C.-G. Eur. J. Pharmacol. 2018, 826, 140. http://doi.org/10.1016/j.ejphar.2018.02.048

8. Van Eldik, L. J.; Carrillo, M. C.; Cole, P. E.; Feuerbach, D.; Greenberg, B. D.; Hendrix, J. A.; Kennedy, M.; Kozauer, N.; Margolin, R. A.; Molinuevo, J. L.; Mueller, R.; Ransohoff, R. M.; Wilcock, D. M.; Bain, L.; Bales, K. Alzheimers Dement. 2016, 2, 99. http://doi.org/10.1016/i.trci.2016.05.001

9. Prasad, N. K. Mechanisms of Aging and Development 2017, 162, 63. http://doi.org/10.1016/i.mad.2016.12.003

10. Wang, D.; Hu, M.; Li, X.; Zhang, D.; Chen. C.; Fu, J.; Shao, S.; Shi, G.; Zhou, Y.; Wu, S.; Zhang, T. Eur. J. Med. Chem. 2019, 168, 207. http://doi.org/10.1016/j.ejmech.2019.02.053

11. Stefanini, C.; Colivicchi, M. A.; Della Corte, L.; Ward, R. J.; De Witte, P.; Lallemand, F.; Hemming, K.; Pitard, A.; Page M. I.; Nayak, K.; Dexter, D. T. J. Alcohol. Drug Depend. 2014, 2, 150. http://doi.org/10.4172/2329-6488.1000150

12. Velagapudi, R.; Jamshaid, F.; Lepiarz, I.; Katola, F. O.; Hemming, K.; Olajide, O. A. Int. Immunopharmacol. 2019, 77, 105951.

http://doi.org/10.1016/i.intimp.2019.105951

13. Hemming K.; Chambers C. S.; Jamshaid F.; O'Gorman P. A. Molecules 2014, 19, 16737. http://doi.org/10.3390/molecules191016737

14. Abbot, V.; Sharma, P.; Dhiman, S.; Noolvi, M. N.; Patel, H. M.; Bhardwaj, V. RSC Adv., 2017, 7, 28313. http://doi.org/10.1039/c6ra24662a 
15. Desmidt, T.; Delrieu, J.; Lebouvier, T.; Robert, G.; David, R.; Balageas, A.-C.; Surget, A.; Belzung, C.; Arlicot, N.; Ribeiro, M.-J.; Payoux, P.; Vellas, B.; El-Hage, W.; Tavernier, E. ; Camus, V. Neurobiology of Aging 2019, $84,61$. http://doi.org/10.1016/j.neurobiolaging.2019.08.008

16. Revot, T. D.; Li, G.; Cook, J. M.; Sibille, E. ACS Chem. Neurosci. 2019, 10, 2088. http://doi.org/10.1021/acschemneuro.9b00148

17. Li, G.; Stephen, M. R.; Kodali, R.; Zahn, N. M.; Poe, M. M.; Tiruveedhula, V. V. N. P. B.; Huber, A. T.; Schussman, M. K.; Qualmann, K.; Panhans, C. M.; Raddatz, N. J.; Baker, D. A.; Prevot, T. D.; Banasr, M.; Sibille, E.; Arnold, L. A.; Cook, J. M. Arkivoc 2018, iv, 158.

http://doi.org/10.24820/ark.5550190.p010.460

18. Li, X.; Yu, J.; Atack, J. R.; Cook, J. M. Med. Chem. Res. 2004, 13, 259. http://doi.org/10.1007/s00044-004-0033-7

19. Xu, N. Z.; Ernst, M.; Treven, M.; Cerne, R.; Wakulchik, M.; Li, X.; Jones, T. M.; Gleason, S. D.; Morrow, D.; Schkeryantz, J. M.; Rahman, M. T.; Li, G.; Poe, M. M.; Cook, J. M.; Witkin, J. M., Psychopharmacology 2018, 235, 1151.

http://doi.org/10.1007/s00213-018-4832-9

20. Huang, Q.; He, X.; Ma, C.; Liu, R.; Yu, S.; Dayer, C. A.; Wenger, G. R.; McKernan, R.; Cook, J. M. J. Med. Chem. 2000, 43, 71.

http://doi.org/10.1021/jm990341r

21. Hamasharif, M. S.; Smith, O. E. P.; Curran, C. J.; Hemming, K. ACS Omega, 2017, 2, 1222. http://doi.org/10.1021/acsomega.7b00211

22. Bozorov. K.; Zhao, J.; Aisa, H. A. Bioorg. Med. Chem. 2019, 27, 3511. http://doi.org/10.1016/i.bmc.2019.07.005

23. Dorababu, A. Bioorg. Chem. 2019, 93, 103299. http://doi.org/10.1016/j.bioorg.2019.103299

24. Yerrabelly, J. R.; Mallepaka, P.; Russ. J. Gen. Chem. 2020, 90, 911. http://doi.org/10.1134/S1070363220050266

25. Gregson, S. J.; Masterson, L. A.; Wei, B.; Pillow, T. H.; Spencer, S. D.; Kang, G.-D.; Yu, S.-F.; Raab, H.; Lau, J.; Li, G.; Lewis Phillips, G. D.; Gunzner-Toste, J.; Safina, B. S.; Ohri, R.; Darwish, M.; Kozak, K. R.; de la CruzChuh, J.; Polson, A.; Flygare, J. A.; Howard, P. W. J. Med. Chem. 2017, 60, 9490.

http://doi.org/10.1021/acs.jmedchem.7b00736

26. Kamal, A.; Prabhakar, S.; Ramaiah, M. J.; Reddy, P. V.; Reddy, Ch. R.; Mullareddy, A.; Shankaraiah, N.; Reddy, T. L. N.; Pushpavalli, S. N. C. V. L.; Pal-Bhadra, M. Eur. J. Med. Chem. 2011, 46, 3820. http://doi.org/10.1016/i/ejmech.2011.05.050

27. Kamal, A.; Ramu, R.; Khanna, G. B. R.; Saxena, A. K.; Shanmugavel, M.; Pandita, R. M. Arkivoc 2005, iii, 83. http://doi.org/10.3998/ark.5550190.0006.311

28. Mehrazar, M.; Hassankalhori, M.; Toolabi, M.; Goli, F.; Moghimi, S.; Nadri, H.; Bukhari, S. N. A.; Firoozpour, L.; Foroumadi, A. Molecular Diversity 2019. In press, published on-line. http://doi.org/10.1007/s11030-019-10008-x

29. Gao, G.-Y.; Li, D.-J.; Keung, W. M. Bioorg. Med. Chem. 2003, 11, 4069. https://doi.org/10.1016/S0968-0896(03)00397-3

30. Wang, W.; He, Y.; Xu, P.; You, Q.; Xiai, H.; Xiang, H.; Bioorg. Med. Chem. 2015, 23, 4428. http://doi.org/10.1016/j.bmc.2015.06.032

31. Kim, D. H. J. Heterocycl. Chem., 1975, 12, 1323. 
http://doi.org/10.1002/jhet.5570120647

32. Pettersson, B.; Hasimbegovic, V.; Bergman, J. J. Org. Chem., 2011, 76, 1554.

http://doi.org/10.1021/jo101864n

33. Preshlock, S.; Calderwood, S.; Verhoog, S.; Tredwell, M.; Huiban, M.; Hienzsch, A.; Gruber, S.; Wilson, T. C.; Taylor, N. J.; Cailly, T.; Schedler, M.; Collier, T. L.; Passchier, J.; Smits, R.; Mollitor, J.; Hoepping, A.; Mueller, M; Genicot, C.; Mercier, J.; Gouverneur, V. Chem. Commun., 2016, 52, 8361.

http://doi.org/10.1039/c6cc03295h

34. Lindner, A. S.; Geist, E.; Gjikaj, M.; Schmidt, A. J. Heterocycl. Chem., 2014, 51, 423.

http://doi.org/10.1002/jhet.1775

35. Yang, J.; Teng, Y.; Ara, S.; Rallapall, S.; Cook, J. M. Synthesis, 2009, 1036.

http://doi.org/10.1055/s-0028-1083358

36. Liu, R.; Hu, R. J.; Zhang, P.; Skolnick, P.; Cook, J. M. J. Med. Chem., 1996, 39, 1928.

https://doi.org/10.1021/jm950887n

37. Cook, J. M.; Clayton, T.; Johnson, Y. T.; Rallapalli, S.; Han, D. US Patent, 2009, US20100130479A1.

38. Scudiero, D. A.; Shoemaker, R. H.; Paull, K. D.; Monks, A.; Tierney, S.; Nofziger, T. H.; Currens, M. J.; Seniff, D.; Boyd, M. R. Cancer Res., 1988, 48, 4827.

http://cancerres.aacrjournals.org/content/48/17/4827

39. Henn, A.; Lund, S.; Hedtjärn, M.; Schrattenholz, A.; Pörzgen, P.; Leist, M. ALTEX, 2009, 26, 83. http://doi.org/10.14573/altex.2009.2.83

40. Parakalan, R.; Jiang, B.; Nimmi, B.; Janani, M.; Jayapal, M.; Lu, J.; Tay, S. S. W.; Ling, E.-A.; Dheen, S. T. BMC Neurosci., 2012, 13, 64.

http://doi.org/10.1186/1471-2202-13-64

41. Bolós, M.; Perea Juan, R.; Avila, J. Biomol. Concepts, 2017, 8, 37.

http://doi.org/1515/bmc-2016-0029

42. Akiyama, H.; Barger, S.; Barnum, S.; Bradt, B.; Bauer, J.; Cole, G. M.; Cooper, N. R.; Eikelenboom, P.;

Emmerling, M; Fiebich, B. L.; Finch, C. E.; Frautschy, S.; Griffin, W. S. T.; Hampel, H. ; Hull, M.; Landreth, G.; Lue, L. F.; Mrak, R.; Mackenzie, I. R.; McGeer, P. L.; O’Banion, M. K.; Pachter, J.; Pasinetti, G.; PlataSalaman, C.; Rogers, J.; Rydel, R.; Shen, Y.; Streit, W.; Strohmeyer, R.; Tooyoma, I.; Van Muiswinkel, F. L.; Veerhuis, R.; Walker, D.; Webster, S.; Wegrzyniak, B.; Wenk G.; Wyss-Coray, T. Neurobiol. Aging, 2000, 21, 383.

http://doi.org/10.1016/S0197-4580(00)00124-X

43. Sun, J.; Zhang, X.; Broderick, M.; Fein, H. Sensors, 2003, 3, 276.

https://doi.org/10.3390/s30800276

44. Wright Jr., W. B.; Brabander, H. J.; Greenblatt, E. N.; Day, I. P.; Hardy Jr., R. A. J. Med. Chem. 1978, 21, 1087.

DOI: http://doi.org/10.1021/jm00208a017

This paper is an open access article distributed under the terms of the Creative Commons Attribution (CC BY) license (http://creativecommons.org/licenses/by/4.0/) 